\title{
Article
}

\section{Psychopathy and trauma: Exploring a potential association}

Ireland, Jane Louise, Mann, Sophie, Lewis, Michael, Ozanne, Rebecca Louise, McNeill, Kimberley and Ireland, Carol Ann

Available at http://clok.uclan.ac.uk/31338/

Ireland, Jane Louise ORCID: 0000-0002-5117-5930, Mann, Sophie, Lewis, Michael ORCID: 0000-0001-5567-3569, Ozanne, Rebecca Louise, McNeill, Kimberley and Ireland, Carol Ann ORCID: 0000-0001-7310-2903 (2020) Psychopathy and trauma: Exploring a potential association. International Journal of Law and Psychiatry, 69 . p. 101543. ISSN 0160-2527

It is advisable to refer to the publisher's version if you intend to cite from the work. http://dx.doi.org/10.1016/j.ijlp.2020.101543

For more information about UCLan's research in this area go to http://www.uclan.ac.uk/researchgroups/ and search for < name of research Group>.

For information about Research generally at UCLan please go to http://www.uclan.ac.uk/research/

All outputs in CLoK are protected by Intellectual Property Rights law, including Copyright law. Copyright, IPR and Moral Rights for the works on this site are retained by the individual authors and/or other copyright owners. Terms and conditions for use of this material are defined in the policies page.

\section{CLoK}

Central Lancashire online Knowledge www.clok.uclan.ac.uk

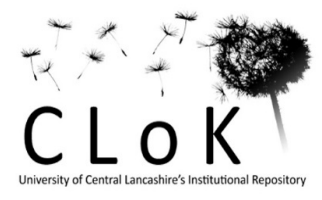


Psychopathy and trauma: Exploring a potential association

Jane L. Ireland*, Sophie Mann, Michael Lewis, Rebecca Ozanne, Kimberley McNeill, Carol A. Ireland

School of Psychology, University of Central Lancashire, Preston \& Ashworth Research Centre, Mersey Care NHS Trust, Liverpool, UK.

*Corresponding author: JLIreland1@uclan.ac.uk 


\begin{abstract}
This research presents a series of linked studies exploring the association between psychopathy and trauma. It comprises a systematic review $(\mathrm{n}=58)$, followed by an expert Delphi $(n=19)$, and patient file trawl using a male forensic psychiatric patient sample $(n=66)$. An association between psychopathy and developmental trauma was predicted. It was further predicted that different types of trauma would be associated with different subtypes of psychopathy and that the severity of trauma would be important. The systematic review identified the following core themes: presence of Post-Traumatic Stress Disorder and/or symptoms; trauma type; trauma/abuse variables; and sex differences. The ensuing Delphi study indicated the specific variant of psychopathy to be important, with secondary psychopathy particularly relevant. The final study found that the severity of developmental trauma related differentially to primary and secondary psychopathy. Implications and directions for future research are discussed, most notably with regards to the conceptualisation of psychopathy.
\end{abstract}

KEYWORDS: Psychopathy; Trauma; Developmental trauma; Personality disorder 


\section{Introduction}

Psychopathy is a personality type characterised by antisocial behaviour, a lack of empathy, shallow affect, manipulation of others, grandiosity, poor behavioural control and impulsivity (Cleckley, 1988; Hare, 1980, 1991; Hicks, Markon, Patrick, Krueger \& Newman 2004; Hicks, Vaidyanathan \& Patrick, 2010). Although sharing some traits with antisocial personality, psychopathy is considered a broader concept that moves beyond behaviour to capture a wider range of personality traits, including those more commonly associated with narcissism, borderline and histrionic, namely the Cluster B personality types (e.g. Sarkar, Clark \& Deeley, 2011). Although comprising antisocial personality, psychopathy should not be used synonymously with it; instead, there should be consideration of the broader elements of personality contributing to psychopathy (Hermann, 2017). Indeed, Ogloff, Campbell \& Shepherd (2016) noted, how, in an offender sample, high levels of psychopathy associated with a diagnosis of antisocial personality disorder in $65 \%$ of cases, but the reverse was not true; having antisocial personality disorder did not automatically lead to a conclusion of high levels of psychopathy, with only $5.5 \%$ of those with antisocial personality disorder high in psychopathic traits. This therefore indicated an asymmetric relationship between antisocial personality and psychopathy (Ogloff et al, 2016). Nevertheless, it is the combination of (high) psychopathy and antisocial personality that becomes of value, with the combination considered an extreme form of antisocial personality disorder. Psychopathy, as a concept, has been considered an acute manifestation of criminality, with this captured well in the proposed Unified Theory of Crime (DeLisi, 2009, 2016). This considers psychopathy to be the motivation for offending as opposed to a mere correlate.

Prevalence for rates of psychopathy vary, but figures from male offender samples estimate the rate to be approximately 6 to 18\% (Coid et al., 2009; Douglas, Ogloff, Nicholls \& Grant, 1999; Hare, 2003; Neumann, Hare \& Pardini, 2015). Whilst these prevalence figures do not appear particularly high, psychopathic individuals are considered costly to society; they commit more 
versatile crimes at a greater frequency and are three to four times more likely to violently recidivate than other offenders (Douglas, Vincent \& Edens, 2006; DeLisi, 2009, 2016; Hart \& Hare, 1996). Moreover, a community sample found that whilst less than $1 \%$ of the general population presented with psychopathy, they were responsible for nearly 20\% of violent crimes (Coid \& Yang, 2011).

Developmental, biological, cognitive, social and behavioural explanations are all proposed to explain the development of psychopathy (Blair, Peschardt, Budhani, Mitchell \& Pine, 2006). Genetic and neural explanations argue that abnormalities and deficits in neural connectivity occurring within various regions of the brain (e.g. paralimbic regions) affect information integration, thus leading to irregularities in externalising behaviours, cognitive and affective processing, and moral behaviour, which may underlie the emergence of psychopathic personality (Blair et al., 2006; Hamilton, Hiatt-Racer \& Newman, 2015; Hare \& Neumann, 2008; Kiehl, 2006; Kiehl \& Hoffman, 2011; Yang \& Raine, 2009).

In terms of social and environmental explanations, it appears there may be a potential relationship between factors associated with antisocial behaviour, such as conduct disorder problems, impulsivity, childhood victimisation, and later psychopathic traits (Piquero, Farrington, Fontaine, Vincent, Coid \& Ullrich, 2012; Weiler \& Widom, 1996). Parental anti-sociality and negativity are also considered predictors for adult psychopathy due to the negative impact this has on child development (Frick, Kimonis, Dandreaux \& Farell, 2003; Harris, Rice \& Lalumière, 2001; Krischer \& Sevecke, 2008). In addition, an interaction between low child anxiety with low levels of parental warmth and support and inconsistent punishment has also been found to make children vulnerable to the manifestation of callous unemotional (CU) traits (Bayliss, Miller \& Henderson, 2010). CU traits are similar to the affective deficits seen in psychopathic individuals and can be a precursor to adult psychopathy (Kimonis, Fanti, Isoma \& Donoghue, 2013), with emotional dysfunction typically cited as being fundamental to the psychopathy diagnosis (Blair et al., 2016). 
Overall, it would appear environmental and social theories of psychopathy suggest that an adverse environment (e.g. including parent anti-sociality, childhood trauma and low parental warmth) can negatively influence a child's developing personality and emotions, predisposing them to the emergence of psychopathic traits (Porter, 1996; Schimmenti \& Caretti, 2014; Schimmenti, Passanisi, Pace, Manzella, Di Carlo \& Caretti, 2014).

Psychopathy is further recognised as a multi-faceted concept, arguably comprised of four main facets, confirmed across several large studies (e.g. Hare \& Neumann, 2005; Falkenbach, Stern \& Creevy, 2014; Neumann, Hare \& Newman, 2007; Vitacco, Neumann \& Jackson, 2005; Vitacco, Rogers, Neumann, Harrison \& Vincent, 2005). These four facets, namely, interpersonal, affective, lifestyle and antisocial are grouped under two main factors, with factor one covering the interpersonal and affective facets and the latter two facets captured by factor two (Hare \& Neumann, 2005, 2008; Zwets, Hornsveld, Neumann, Muris \& van Marle, 2015). Research has further divided psychopathy into two major subtypes; primary, involving planned aggression, grandiosity and lack of affect, and secondary, involving reactive aggression, impulsivity and antisocial behaviour (Blonigen, Sullivan, Hicks \& Patrick, 2012; Brinkley, Schmitt, Smith \& Newman, 2001; Porter, 1996; Yildirim \& Derksen, 2015). Secondary is generally considered associated with emotional functioning challenges and primarily representative of an absence of empathy/emotional consideration of others (Brinkley et al., 2001; Hare \& Neumann, 2005, 2008; Guay et al., 2007; Yildirim \& Derksen, 2015).

The distinction made between psychopathy subtypes is important, as several studies suggest the development of secondary psychopathy, in particular, can be explained via adverse childhood experiences, including developmental trauma (Hicks et al., 2004; Lang, Af Klinteberg \& Alm, 2002; Schimmenti et al., 2014). Secondary psychopathy has also been argued by some to represent more of an 'acquired' disorder (Blackburn, Logan, Donnelly \& Renwick, 2008; Karpman, 1941; Kerig \& Becker, 2010; Porter, 1996; Yildirim \& Derksen, 2015). Conversely, 
primary psychopathy is thought of as more hereditary and related to genetic predispositions and neural abnormalities (Blair, 2003; Karpman, 1941; Kiehl \& Hoffman, 2011; Kiehl, Smith, Hare, Forster, Brink \& Liddle, 2001; Skeem, Johansson, Andershed, Kerr \& Louden, 2007).

According to some (e.g. Anderson \& Kiehl, 2014; Blair, 2006; Kiehl \& Hoffman, 2011), psychopathy is currently better understood by genetic and neural theories, as these provide evidence accounting for the emotional dysfunction and reduced responsiveness often seen in psychopathy. However, this fails to take into consideration the increased emotional responsiveness and reactive behaviour that is observed in those presenting with secondary psychopathy, which is thought to be related to environmental factors, such as childhood trauma and parental anti-sociality (Hicks et al., 2004; Lang, Af Klinteberg \& Alm, 2002; Schimmenti et al., 2014). This suggests psychopathy cannot be explained solely by biological explanations and may be better understood as a complex interaction between biological, environmental and social factors (Hare, 1993; Ogloff, 2006; Porter, 1996; Schimmenti et al., 2015). One such core factor to perhaps capture is that of trauma.

Trauma is defined as an emotional response to a distressing event, such as a physical attack, sexual abuse or natural disaster (American Psychological Association, 2016). Long-term reactions can include unpredictable emotions, flashbacks (re-experiencing) and strained relationships (American Psychological Association, 2016). DSM-V has made several changes to how post traumatic stress disorder is defined for diagnostic purposes but, in summary, defines it as exposure to actual or threatened death, serious injury or sexual violation. It refers to the exposure being directly experienced, witnessed, learnt about (involving a close family member or friend) and/or first-hand repeated or extreme exposure to aversive details of a trauma (American Psychiatric Association, 2013). Developmental trauma, however, encompasses all traumatic experiences that occur in childhood and refer to an adverse event that occurs repeatedly (Atchinson \& Morkut, 2011; Courtois, 2004; Sar, 2011), with this capturing exposure to violence (Atchinson \& Morkut, 
2011; Sar, 2011). Child trauma theory argues that children are particularly at risk for severe, longterm behavioural and emotional impairments and they are reported to respond differently to adults, following trauma exposure (Alisic, Jongmans, van Wesel \& Kleber, 2011). Indeed, trauma is considered to have the greatest negative effect in the first decade of life (van der Kolk, Roth, Pelcovitz, Sunday \& Spinazzola, 2005). This is considered a result of the emotional systems of children not being fully developed and trauma exposure leading to problems with aggression, impulse regulation, dissociation, interpersonal interactions and disturbances of attribution (D’Andrea, Ford, Stolbach, Spinazzola \& van der Kolk, 2012; van der Kolk et al., 2005). Moreover, a child's environment should normally allow them to develop positive skills and functioning, such as the capacity for trust, self-control, social understanding and empathy; all of which can be compromised by developmental trauma (Cicchetti \& Toth, 2005; Cicchetti \& Valentino, 2006).

Developmental trauma disorder has been associated with affect and behaviour dysregulation, aggression, impulsive risk taking, attribution errors and maladaptive schemas, as well as problems with interpersonal relationships (Atchinson \& Morkut, 2011; National Children's Traumatic Stress Network, 2003; Teisl \& Cicchetti, 2008; D’Andrea et al., 2012). All of these can also be associated with psychopathy (Hicks et al., 2010), thereby allowing for a conceptual link to be made. In addition, a specific type of developmental trauma, namely Betrayal Trauma (BT), is perhaps useful to note at this point. This can occur when an abused victim also feels raised levels of betrayal owing to the abuser being a close relative or caregiver, someone who the victim trusted and/or depended on (Freyd, 1994). Betrayal Trauma Theory (Freyd, 1994; Sivers, Schooler \& Freyd, 2002) argues how an abuse victim may "block" knowledge of the trauma, leading to emotional detachment to preserve the relationship for attachment purposes. This can include emergence of a dissociative experience, where an individual will dissociate their trauma from conscious awareness, referred to as traumatic dissociation (Sivers et al, 2002). Betrayal trauma 
has further been described as a withdrawal of emotional awareness relating to this abuse-betrayal (Kerig, Bennett, Thompson \& Becker, 2012). Higher levels of betrayal trauma have been shown to be related to higher levels of Post-Traumatic Stress Disorder (PTSD; APA, 2016) and to certain traits of psychopathy, such as impulsive and antisocial aspects (Cima, Smeets \& Jelicic, 2007).

The empirical link between developmental trauma and psychopathy remains surprisingly understudied. It appears that psychopathy cannot be explained by environmental or biological factors alone (Blair et al., 2006; Hare, 1993; Ogloff, 2006; Schimmenti et al., 2015). There have been early references made to trauma exposure being associated with psychopathy (Marshall \& Cooke, 1999), with this notion later supported based on case study material (Nørbech, Crittenden \& Hartmann, 2013), and correlations between traumatic experiences and psychopathy (Warren \& South, 2006). Other research has suggested an association between early victimisation, adverse childhood circumstances and psychopathy in adulthood, whereby those exposed to early adverse conditions, such as childhood abuse and victimisation, present with higher levels of psychopathy than those with no such history (Krischer \& Sevecke, 2008; Lang et al., 2002). More recent research has demonstrated that of those with psychopathy scores above $30,70 \%$ had experienced severe multiple relational trauma (e.g. neglect, abuse by relatives) and all had attachment problems in childhood and adulthood (Schimmenti et al., 2014).

Furthermore, an association has been reported between trauma and CU traits in antisocial youth, mediated by emotional numbing (Kerig, Bennett, Thompson \& Becker, 2012). It was thought that some youth may present with a defensive response to the trauma whereby their emotional reactions diminish, and they become detached, acting to reduce trauma impact (Kerig \& Becker, 2010; Kerig et al., 2012), at least in the short to mid-term. This emotional response has been discussed by Porter (1996), who proposed a dissociative mechanism for the development of secondary psychopathy. Porter (1996) suggested that some children have the potential for empathy and normal affect but, due to high levels of abuse, emotions become unconnected to cognitions 
and behaviours. This then becomes an effective defensive mechanism, which is negatively reinforced, as the child is better able to deal with chronic and intense feelings of distress produced by the abuse, due to this disconnection. Porter (1996) argues that secondary psychopathy can consequently be acquired through learning to deal with painful experiences in this manner.

Porter's (1996) reasoning is supported by research suggesting that emotional abuse can lead to affective deficits (Weiler \& Widom, 1996). The authors suggested that the relationship between childhood victimisation, abuse and later violence, is mediated by psychopathy. Therefore, it was postulated that early abuse may act to desensitise a child to distressing experiences, making them less emotionally responsive and unable to regulate their emotions. Other findings support those of Weiler and Widom (1996); self-reported abuse experiences were found associated with more psychopathic factor two type behaviours (Poythress, Skeem \& Lilienfeld, 2006), and offenders with a history of being sexually abused as a child scored higher on the PCL-R overall and on the interpersonal, lifestyle and antisocial facets (Graham, Kimonis, Wasserman \& Kline, 2012). Research has also proposed that abuse types may be differentially associated with the factors of psychopathy, namely physical abuse with factor two, and emotional abuse and neglect with factor one (Borja \& Ostrosky, 2013; Campbell, Porter \& Santor, 2004; Poythress et al., 2006;). Others have indicated that the severity of childhood abuse is also important to consider, with severe physical abuse associated with increased reactive aggression when PCL-R scores were also high (Kolla, Malcolm, Attard, Arenovich, Blackwood \& Hodgins, 2013). Moreover, those with Antisocial Personality Disorder (ASPD) and psychopathy have reported more severe physical abuse than those without the complicating feature of psychopathy (Kolla et al., 2013).

Since the study of Weiler and Widom (1996) there has clearly been more evidence provided, which suggests a potential association between early trauma and psychopathy; however, the exact nature of such an association requires more attention. Additionally, research has mainly focused on dissocial youth and prisoners, and often overlooks the development of both subtypes 
of psychopathy. Research also tends to be preliminary and limited in scope. Consequently, any proposed relationship between psychopathy and trauma is far from conclusive since not all individuals who experience trauma present with psychopathy, with some finding no such relationship (Kolla et al., 2014; Ometto et al., 2016). This highlights value in exploring in more detail the presence or absence of any such association.

The current series of studies aim to build on the limited research conducted to date by exploring in depth trauma and the possible association that this may have with psychopathy. Comprising a systematic review, expert Delphi and file trawl of male forensic psychiatric patients, the current set of studies predicted that:

1.) There would be an association between psychopathy and developmental and betrayal trauma, with evidence of trauma associated with raised levels of psychopathy.

2.) Different types of trauma would be associated with different subtypes of psychopathy, both secondary and primary psychopathy.

3.) The severity of trauma would be associated with higher levels of psychopathy.

Study one: A systematic review

A systematic review of the literature was conducted using PRISMA guidelines (Prisma, 2009a, 2009b). All available primary sources were included (e.g. peer reviewed journals and dissertations) from four databases: PsycINFO (759 papers), MEDLINE (458 papers), CINAHL Complete (54 papers), and PsycARTICLES (50 papers).

Key words were 'Psychopath* AND AB (Trauma* OR Abuse OR Neglect OR Maltreatment) NOT AB ('psychopathology' OR 'psychopathological')'. The search was limited to words included in the abstract. No date limit was set. Relevant references were also sourced from the references of included papers and relevant reviews. To meet the selection criteria, papers could 
not be duplicates; they must have discussed the effect of psychological trauma on the development of psychopathy and must be in English. Only primary sources were included.

Four raters were involved, with a minimum of $10 \%$ of their ratings examined. Inter-rater reliability was based on two categories: included or not included. For abstract screening, Cohen's Kappa ranged from .85 to .88 , demonstrating excellent reliability. Overall reliability for full text screening was excellent at 93\% (14 agreements and one disagreement). Agreement on 10\% of each rater's coding of study quality was also considered, with a good level of agreement (75\%) found. Where there was disagreement, discussions were held, and relevant articles re-visited. Inter-rater reliability was further conducted on the overall themes, with full agreement noted.

\section{Quality assessment}

Consistent with the alterations made by Norman, Byambaa, De, Butchart, Scott and Vos (2012), the Newcastle-Ottawa Scale for assessing observational studies was adapted to examine study quality. To breakdown the quality assessment: 22 manuscripts adopted a suitable sample for the aims of the present research; 46 utilised a single sample with measures of abuse or psychopathy administered to split participants into those exposed/not exposed to trauma, or indeed, assessed trauma along a continuum; six papers used substantiated records; 30 adopted a validated measure of psychopathy; 29 studies were noted to make an effort to control confounding variables; and 24 included the source of funding.

Results

A total of 1,321 titles were returned in the original search, with 58 retained for analysis. Figure 1 notes the 58 papers that were included in the final analysis. Following exploration of references (of both included studies and relevant review papers), three additional manuscripts were added. Studies included in the review were authored in western countries, namely USA ( $n$ $=38)$, Belgium $(n=1)$, Canada $(n=4)$, Italy $(n=2)$, Germany $(n=1)$, Finland $(n=1)$, Sweden 
$(n=2)$, Switzerland $(n=1)$, Netherlands $(n=1)$ and the UK $(n=1)$. The remaining six studies had authors in more than one country.

\section{$<<$ Insert Figure 1 here $>>$}

Sixteen studies recruited a forensic child/adolescent sample and 22 sampled adult offenders. A number of these also used general population controls. Participants were predominantly men. Studies used variations of the Psychopathy Checklist $(n=36)$, including the revised version $(n=22)$ or the youth version $(n=7)$. Other measures included the Antisocial Process Screening Device $(n=2)$, the Inventory of Callous and Unemotional traits $(n=3)$, the Minnesota Multiphasic Personality Inventory $(n=2)$, the Youth Psychopathy Traits Inventory $(n$ $=3)$, the Psychopathic Personality Inventory $(n=2)$, and the Levenson Self-report Psychopathy Scale $(n=2)$. Regarding child abuse and neglect in relation to trauma, nine studies used the Childhood Trauma Questionnaire and a further three administered the Child Abuse and Trauma Scale. Other trauma measures included Loss of a Parent, Placement in an Institution, Parental Conflict, and Community Violence.

Four salient themes, with accompanying subthemes, were identified from the thematic analysis (See Braun \& Clarke, 2006, for the steps involved in this analysis) of the review. These were as follows:

1.) Presence of Post-Traumatic Stress Disorder (PTSD) and/or symptoms: Symptoms consistent with PTSD were reported for individuals presenting with psychopathy, with this extended to also capture those with higher levels of CU traits (Sharf et al., 2014). Past research indicated a lack of PTSD diagnosis in the psychopathy versus non-psychopathy group (Warren \& South, 2006), with others also citing lower levels of trauma connected to psychopathy (Pham, 2012). Fingerson (2008), however, argues that this may be the case for non-interpersonal trauma, where higher levels of psychopathy related to lower current distress (Fingerson, 2008). Blonigen et al. (2012) further noted differences in the association between PTSD and psychopathy 
components, reporting the strongest association with the antisocial facet. This shares some consistency with Tatar, Cauffman, Skeem and Kimonis (2012) who found individuals exhibiting secondary psychopathy to report higher levels of previous PTSD symptoms compared to those with primary or no psychopathy. No differences across psychopathy subtypes for current PTSD symptoms were reported.

Thus, there is some acknowledgement of trauma being associated with psychopathy, yet a formal clinical diagnosis of PTSD appears to be absent in the psychopathy literature. There is a preference instead to capture PTSD, or traits of, via self-report. The limitations of this are clearly evidenced in terms of response bias, and, consequently, the reliability and validity of symptoms. Any interpretation of the literature needs to be mindful of this.

2.) Type of trauma: Specific forms of traumatic experiences were being indicated as important factors. Core subthemes included:

Childhood maltreatment. This was the most commonly researched factor, with raised levels of psychopathy associated with reports of childhood abuse (Dargis, Newman \& Koenigs, 2015; Edwards, 2013; Koivisto, \& Haapasalo, 1996; Leach \& Meloy, 1999; Ometto et al., 2016; O'Neill, Lidz \& Heilbrun, 2003; Schimmenti et al., 2014). This included exposure to neglect (Graham et al., 2012; Koivisto \& Haapasalo, 1996; ; Ometto et al., 2016; Weiler \& Widom, 1996; Schraft et al., 2013), physical neglect (Dargis et al., 2015; Ometto et al., 2016), physical abuse (Dargis et al., 2015; Dernevik, Sepa, Philipson, \& Bragesjö, 2001; Gao, Raine, Chan, Venables, \& Mednick, 2010; Hunter, Figueredo \& Malamuth, 2010; Leach \& Meloy, 1999; Reyes, 2013; Verona et al., 2005), emotional abuse (Daversa \& Knight, 2007; Krischer \& Sevecke, 2008; Schimmenti et al., 2015), and sexual abuse (Graham et al., 2012). It was also noted that a larger proportion of prisoners with primary psychopathy had experienced sexual abuse when compared to prisoners without this psychopathy subtype (Hicks, et al., 2010). Those who had experienced physical abuse and neglect were also reported to score significantly higher on CU traits (Fisher, 
2004; Sharf et al., 2014). Differences were also noted in relation to primary and secondary psychopathy, with (high anxiety) secondary psychopathy associated with higher levels of abuse when compared to (low anxiety) primary psychopathy (Kimonis, Frick, Cauffman, Goldweber \& Skeem, 2012; Kimonis, Skeem, Cauffman \& Dmitrieva, 2011).

However, associations were far from consistent, with some reporting the link between childhood maltreatment/abuse and psychopathy to be modest (Graham, Kimonis, Wasserman \& Kline, 2012; Schimmenti, Di Carlo, Passanisi \& Caretti, 2015). Others also reported it as a poor correlator (Fingerson, 2008; Kimonis, Cross, Howard \& Donoghue, 2013; Pham, 2012) or predictor of psychopathy (Fisher, 2004; Stevenson, 2010; Christopher, Lutz-Zois, \& Reinhardt, 2007; Schember, 2008). Furthermore, childhood maltreatment was argued not to differentiate between psychopathy and antisocial personality disorder (Kolla et al., 2014), and was found to associate more strongly with the antisocial and lifestyle components of psychopathy (Poythress, Skeem \& Lilienfeld, 2006).

There was also an indication that physical neglect may be more commonly reported by offenders who were not psychopathic (Cima et al., 2008), or that neglect did not associate with the interpersonal-affective component of psychopathy (Dargis et al., 2015). Associations between physical abuse and psychopathy may relate more to the lifestyle and antisocial factors of psychopathy (Dargis et al., 2015; Graham et al., 2012; Krstic, Knight \& Robertson, 2015; Ometto et al., 2016; Schimmenti et al., 2015).

Thus, there is evidence that maltreatment presents differently across psychopathy-related traits (Kimonis et al., 2013). In addition, emotional numbing has been identified as a mediating factor between $\mathrm{CU}$ traits and betrayal trauma, but not for other forms of trauma, suggesting that the perpetrator of abuse may be an important factor to consider (Kerig, Bennett, Thompson \& Becker, 2012), which is not well captured in the academic literature.

There is inconsistent evidence in relation to emotional abuse, sexual abuse and 
psychopathy, with the former exhibiting a poor link with the disorder overall (Campbell et al., 2004; Dargis et al., 2015; Krstic et al., 2015; Ometto et al., 2016,). However, research has noted it as an influential factor potentially co-varying with the interpersonal and lifestyle features of psychopathy (Krstic et al., 2015; Schimmenti et al., 2015), as well as the antisocial facet (Verona, Hicks \& Patrick, 2005).

Timing of abuse also appears important, with sexual abuse manifesting prior to the age of 15 found to predict psychopathic personality disorder (Ullrich \& Marneros, 2007). Emotional abuse presented with a similar pattern to other forms, exhibiting mixed findings regarding its association with the disorder (Kolla et al., 2014; Krstic et al., 2015; Ometto et al., 2016;). There also remains little clarity over emotional/psychological abuse, as it has been found to relate to various components of psychopathy differently, such as the affective (Krstic et al., 2015) and criminal history and lifestyle facets (Campbell et al., 2004; Dargis et al., 2015; Krischer \& Sevecke, 2008; Schimmenti et al., 2015). There is also inconsistency with regards to this form of trauma and its relationship with the interpersonal component of psychopathy (Dargis et al., 2015; Schimmenti et al., 2015).

Exposure during combat, where a diagnosis of psychopathic constitution was common among soldiers who had past experience of psychological traumas (Linden, Hess \& Jones, 2012), was also noted.

Violence within the family of origin (Stevenson, 2010; Weizmann-Henelius, Gronroos, Putkonen, Eronen, Lindberg \& Hakkanen-Nyholm, 2010). There was indication that familial experiences may be more closely related to the interpersonal characteristics of psychopathy and societal influences on the behavioural features (Marshall \& Cooke, 1999).

Violence within the community (Schraft, Kosson \& Mcbride, 2013). Although higher levels of childhood victimisation were more frequent among those with higher levels of psychopathy, a subgroup was also established that reported low victimisation and had perpetrated extensive 
violence (Lang, Klinteberg \& Alm, 2002). Community violence exposure did not appear to consistently relate to psychopathy (Schember, 2008).

Loss of significant relationship/attachment-related traumas. A disruption to attachment was identified among individuals with psychopathy (Campbell, Porter \& Santor, 2004; Krischer \& Sevecke, 2008; Weizmann-Henelius et al, 2010). However, disruptions in living situation have been found not to relate to psychopathy in some studies (Campbell et al., 2004), although it was noted to be important for young children (Gao, Raine, Chan, Venables \& Mednick, 2010). Supported by Marshall and Cooke (1999), offenders presenting with psychopathy reported significantly more negative institutional experiences when compared to non-psychopathic offenders. Reactive attachment disorder was also found to mediate the relationship between child abuse and neglect, and psychopathy (Schraft, 2015).

Parenting style, with low levels of maternal care relating to higher levels of psychopathy. Although it was felt that this factor may relate to the impact of abuse on psychopathic presentation (Gao et al., 2010).

3.) Trauma/abuse variables, including the subthemes of cumulating effects and developmental stage:

Culminating effects. There is some indication that the relationship between psychological trauma and psychopathy may be stronger when multiple forms of trauma are present (Graham et al., 2012), with experiences of abuse impacting on each other (Daversa \& Knight, 2007). Varying combinations of abuse have also been found to result in higher levels of psychopathy (Krstic et al., 2015).

Developmental stage, with the literature indicating that experiencing trauma early in life can associate with increased levels of psychopathy (Craparo, Schimmenti \& Caretti, 2013).

4.) Sex differences, with an indication of a lack of sex differences in the relationship between psychopathy and trauma, extending this to the role of child neglect (Weiler \& Widom, 
1996) and physical abuse (King, 2014). However, research also indicated that the association between physical abuse and psychopathy was only significant for boys, whereas sexual abuse appeared specific to girls (Weizmann-Henelius et al., 2010). There was also evidence that trauma among delinquent girls associated more with $\mathrm{CU}$ traits and the impulsivity-conduct problem characteristics of psychopathy. For delinquent boys, however, the association appeared to relate solely to impulsivity-conduct problems (Valentine, 2001). Research capturing sex differences was largely descriptive, and constrained to youths, thus ignoring psychopathy presenting in adulthood.

Overall, the systematic review appeared to evidence not only an association between psychopathy and trauma, including its symptoms, that was worthy of further consideration but also a role for developmental trauma and the importance in accounting for psychopathy as a multifaceted concept when considering this area. The majority of included research focused on trauma exposed to within formative years, particularly via those in a position of trust. This brings into focus a role not only for developmental trauma but also betrayal trauma. The review also indicated limitations in the literature base, including a failure to diagnose trauma, with a focus instead on self-report and symptoms. There was also a tendency to consider psychopathy as a global construct or to attend only to psychopathy traits or those aligned to the concept (e.g. Callous Unemotional).

To complement the current enquiry into whether or not psychopathy and trauma are related, the ensuing studies aimed to build on the systematic review by engaging with experts in the field (Study two), both academics and practitioners, to generate their perspectives of any potential association, as well as those likely to be at an increased risk of trauma histories and psychopathy, namely forensic psychiatric patients (Study three). Owing to the indication of developmental and betrayal trauma as potentially appearing key, the focus was on these experiences and their potential association with psychopathy and its components. 


\section{Study two: An expert Delphi}

\section{Participants}

Experts in developmental trauma and/or psychopathy were approached. This incorporated two groups, clinical practitioners and academics. To be recruited, the expert had to have been in clinical practice for over five years with clients who had experienced trauma and/or presented with psychopathy, or, had published over two peer reviewed papers on either psychopathy or developmental trauma. The total number of experts in the Delphi sample was $n=19$ for round one, $(73 \%$ were academics, $36.8 \%$ had clinical experience with psychopathy and $52.6 \%$ had clinical experience with trauma). In round two, $n=16$ (72\% academics, $33 \%$ clinicians experienced with psychopathy and $55.6 \%$ clinicians experienced with trauma ) and in round three, $n=12(46.2 \%$ academics, $15.4 \%$ clinicians experienced with psychopathy and $38.5 \%$ clinicians experienced with trauma).

\section{Method}

Academic experts were identified via the systematic review (i.e. Study one). Additionally, the website researchgate.net was searched using the keywords 'psychopathy' and 'developmental trauma' to identify those active in the research field. To recruit the practitioner expert group, the British Psychological Society and British Association of Behavioural and Cognitive Psychotherapies public directories were used. Those who matched the inclusion criteria were invited to participate and sent an information sheet. If they consented, they were sent a link to the first round of the online survey. In total, over 550 emails were disseminated. Ethical approval was gained from the NHS Research Ethical Committee and the Health Research Authority $(16 / \mathrm{NW} / 0665)$.

\section{Materials}

Round one used a questionnaire containing 19 open ended questions, entered onto 'esurveycreator.com'. The questions were informed by the systematic review. Examples of 
questions included, 'What types of trauma do you consider most damaging to a developing child (i.e. under 18)?', 'For those experiencing abuse, what kind of impact do you think the perpetrator-victim relationship has on the experiencing of trauma?', 'To what extent could there be a link between exposure to trauma as a child and the emergence of psychopathy?', 'Which components of psychopathy do you feel could be most (and least) affected by childhood trauma?' The question, 'How likely do you think it is that a child with developmental trauma would go on to develop psychopathy?' was retained in each round. The questionnaire for round two was created using the themes and subthemes extracted from round one responses, using the Grounded Delphi Method (See Baskerville \& Pries-Heje, 1999; Päivärinta, Pekkola, \& Moe, 2011). These themes then formed both the questions and answer options, which used a Likert scale ( 1 = strongly disagree; 5 $=$ strongly agree) to measure level of agreement.

The final round of the Delphi was a checking round, which gave the expert panel a final opportunity to state if they disagreed with any item. The final round was split into two sections; the first comprised answer options that had reached $60 \%$ agreement or more in the second round and allowed the expert panel to confirm their agreement, or explain why they did not. The second section included options that were close in terms of agreement in round two, thus providing a further opportunity to rate their agreement.

\section{Results}

Information from Delphi round one was coded and grouped into themes using coding procedures informed by Grounded Theory. This comprised of four main phases: Data collection; Identification of codes and subsequent themes; Data prioritisation (i.e. exclusion of lowest agreement items); and, development of ideas from the expert consensus.

\section{Round one}

Eight themes were extracted from round one (see Figure 2). A co-rater was asked to examine the qualitative information from round one and place it into themes so that inter-rater 
reliability could be determined. Percentage agreement between raters was $87.5 \%$. When considering the differences between clinical practitioners and academics, clinicians focused more on the maturation of the child and how developmental trauma affected this; their answers were centred on disruption to child development and violation of expectations, and how these may potentially link to the manifestation of psychopathy. In contrast, academics provided answers that considered more contextual and external factors that may be present for a child experiencing developmental trauma (e.g. severity of trauma, low SES, environmental factors), and how these may impact on the child as well as potentially linking to psychopathy development.

$$
<<\text { Insert Figure } 2 \text { here }>>
$$

\section{Rounds two and three}

The percentage agreement for items scored in rounds two and three can be found in Table 1. The cut off for item consensus was set at $60 \%$, as opposed to the more usual $70 \%$ (moderate) or $80 \%$ (high). This was due to a small sample size, meaning that one participant disagreeing had a notable impact on the agreement levels in round two. An agreement of $70 \%$ was used for the final round, deemed to be a moderate level of agreement for Delphi studies (Hsu \& Sandford, 2007; Rodriguez-Manas et al., 2013). Table 1 presents the items rated in round three, and Table 2 shows those statements achieving the highest levels of agreement and were checked for a final consensus of opinion.

\section{$<<$ Insert Tables 1 and 2 here $>>$}

The final round of the Delphi indicated that experts viewed several statements as key when considering the association between developmental trauma and psychopathy. Firstly, the formation of trust was important, and trauma, particularly Betrayal Trauma, undermined this. Considering there to be a severe impact when a caregiver was the perpetrator also achieved high agreement $(91.7 \%)$, as this was viewed to be detrimental to trust development. Specific developmental trauma symptoms, such as social and relationship problems, were considered as 
least partially responsible for its potential association with psychopathy. However, $91.7 \%$ agreed that difficulties with symptoms, such as self-regulation and disinhibited behaviour, were associated more with the development of secondary psychopathy. Additionally, a lack of emotional development and the impact developmental trauma has on personality development were thought important when considering their association with primary psychopathy, whereas interference with the child's developmental needs was viewed as more important when looking at their association to secondary psychopathy. Betrayal trauma was agreed by $83.3 \%$ of the experts to affect the possibility of abnormal psychopathy emerging due to the child adopting emotional numbing as a defence mechanism to combat the negative effects of trauma. This was then thought to influence a child's ability to develop caring emotions towards others.

Overall, $66.7 \%$ of the sample agreed that it was likely that a child who had experienced developmental trauma could develop secondary psychopathy. In comparison, $58.3 \%$ agreed that developmental trauma could lead to primary psychopathy. The sample also agreed that there may be differential mechanisms for this potential association, as outlined here. The association was further explored in the ensuing study among a high secure psychiatric sample, which was extended to capture an association with Antisocial/Dissocial Personality Disorder.

Study three: Examining forensic clinical case histories

\section{Participants}

All participants were men detained in a high secure psychiatric hospital. Eighty patients consented, with 14 excluded as they did not meet the inclusion criteria, thus leaving a sample of 66 (Mean age $=36.0)$. A priori power analysis was calculated using GPower (Faul, Erdfelder, Buchner \& Lang, 2009), indicating a minimum required sample size of $n=43$. All patients had completed a psychopathy assessment (PCL-R: Psychopathy Checklist Revised; Hare, 2003) or 
had received a diagnosis for a known personality disorder, namely dissocial/antisocial (APD), borderline or narcissistic.

\section{Method}

\section{Procedure}

Consent was sought from Responsible Clinicians (RCs) prior to patients being approached. Suitable patients were then invited to provide consent for research access to their medical records. Ethical approval was gained from the NHS Research Ethical Committee and the Health Research Authority (16/NW/0665).

\section{Materials}

Qualitative information gathered from patient files was entered into data capture sheets created using the Childhood Trauma Questionnaire (CTQ; Bernstein et al., 1994), which comprises of 28 items regarding abuse types. The CTQ has been demonstrated to possess good reliability and validity in examining evidence of childhood trauma (Bernstein et al., 1994; Bernstein, Ahluvalia, Pogge \& Handelsman, 1997). It includes detailed descriptions of developmental trauma types, alongside DSM-5 and ICD-10 definitions of trauma, which were used to determine if events occurring during a patient's childhood qualified as trauma. The first data capture sheet was scored by a second individual to check for validity and inter-rater reliability. The agreement was found to be $80.0 \%$.

Information pertaining to childhood experiences (i.e. the presence of, type, and severity of developmental trauma) was also documented and coded using information adapted from the Modified Maltreatment Classification System (English et al., 1997), which uses codes from one to five (' 5 ' being the most severe) to classify physical, sexual, neglect and emotional childhood abuse. A code of ' 0 ' was given if the abuse type was not present. File information was also reviewed for a personality disorder diagnosis (in accordance with either ICD or DSM) and/or a PCL-R (psychopathy) assessment. This information was captured after the file information had 
been analysed for trauma and other childhood experiences so that there was no assessor bias likely to emerge.

\section{Results}

Of the 66 patients included in the final sample, 17 had completed PCL-R assessments. Of those, 13 had psychopathy; thus, $19.7 \%$ of the sample presented with clinical psychopathy (Mean PCL-R score $=27.5$, Median $=28.5)$. Approximately two thirds of the sample $(60.6 \%, n=40)$ presented with Antisocial/Dissocial Personality Disorder. Levels of trauma across the entire sample was high, with $91 \%$ experiencing trauma of any kind and $72.7 \%$ experiencing multiple developmental traumas. More specifically, 72.7\% $(n=48)$ reported physical trauma (mean severity $1.98 / \mathrm{SD} 1.43) ; 45.5 \%(n=30)$ reported sexual trauma (mean severity $1.45 / \mathrm{SD} 1.78)$; and $84.8 \%(n=56)$ reported emotional/neglect (mean severity 2.0/SD 1.36).

\section{Groups differences: Developmental trauma}

Table 3 displays the frequencies of developmental trauma in those with psychopathy and those without psychopathy, and trauma severity in relation to APD.

$$
<\text { Insert Table } 3 \text { here >> }
$$

Chi square tests were calculated to evaluate group differences between those with psychopathy and those without psychopathy, with Fischer's exact test values used due to smaller sample sizes. There was no difference in developmental trauma levels either overall or across specific trauma types between those with psychopathy and those without. The same was noted in relation to APD, where no differences were found. In addition, no significant differences were noted (using a one-way ANOVA) in relation to trauma severity and APD.

\section{Psychopathy levels and severity of developmental trauma}

To consider if total PCL-R scores could be predicted by trauma severity scores, several linear regressions were calculated. Table 4 displays the results of the regression analyses, calculated for each PCL-R outcome variable. 
$<$ Insert Table 4 here >>

Severity scores did not predict total PCL-R scores. Regarding Factor I (interpersonal) PCL$\mathrm{R}$ scores, these were significantly predicted by increased physical trauma severity $(F(1,14)=$ $5.29, p<.05, \mathrm{R}^{2}=.27, \mathrm{R}^{2}$ Adjusted $=.22$ ), with $28 \%$ of variance in Factor I scores accounted for by physical abuse severity. This suggests that as physical trauma severity increases, Factor I scores would be expected to increase also. Regarding Factor II (criminal history and lifestyle) PCL-R scores, (increased) physical trauma severity was again shown to be a significant predictor variable $\left(F(1,14)=9.54, p<.01, \mathrm{R}^{2}=.41, \mathrm{R}^{2}\right.$ Adjusted $\left.=.36\right)$, with $41 \%$ of variance in Factor II scores accounted for by severity of physical trauma. Factor II scores were also significantly predicted by overall (increased) developmental trauma severity scores $\left(F(1,14)=7.41, p<.05, \mathrm{R}^{2}=.35\right.$, $\mathrm{R}^{2}$ Adjusted $=.29$ ), with $35 \%$ of variance in Factor II scores accounted for by overall trauma severity scores.

\section{Discussion}

The current research demonstrated how the association between psychopathy and trauma is not well understood. The systematic review, although highlighting a potential association between psychopathy and developmental trauma equally demonstrated limitations regarding how trauma had been captured. There has, for example, been a focus on trauma symptoms as opposed to diagnosis, an absence of consideration of the mechanisms by which psychopathy may develop from trauma, and a lack of longitudinal research, leading to conclusions based on associations. The definitions of psychopathy applied also varied. Regardless, there is an indication of a link between psychopathy and trauma worthy of further consideration, particularly one that accounts for developmental (including betrayal) trauma, the nature of reported trauma, and components of psychopathy. Indeed, the Delphi component of the current research highlighted high levels of agreement regarding developmental trauma as an important component of psychopathy, suggesting there is a clear developmental consideration to potentially account for. Equally, there 
was an acceptance of trust being a core consideration, with the expert sample agreeing that trust (or rather lack of) was relevant due to the negative impact this has on future relationships and social interactions. This would appear consistent with the concept of betrayal trauma (Freyd, 1994), thought underpinned by the erosion of trust, notably during crucial periods of maturation. Thus, both the systematic review and Delphi highlighted similarities in this regard and a need to acknowledge a relationship between developmental/betrayal trauma and psychopathy. This offered some support for the prediction that there would be an association between psychopathy and both developmental and betrayal trauma, although articulation of betrayal trauma was unclear. In addition, the missing component from the literature and Delphi study appeared to represent trauma experiences examined directly in populations at a raised risk of personality challenges, including psychopathy, and its potential association with personality disturbance. The final study captured this, demonstrating high levels of developmental trauma in the sample, with virtually all (91.7\%) having experienced some form of adverse childhood experience.

Continuing with the importance of trauma type, emotional trauma was agreed on by $75 \%$ of the expert sample as likely to potentially lead to the development of secondary psychopathy, whereas multiple trauma types were agreed to make primary psychopathy development more likely. The former observation is consistent with research highlighting the importance of accounting for emotional abuse with psychopathy development (Weiler \& Widom, 1996), although the research field has tended to link this more to the interpersonal components of psychopathy (i.e. Factor 1) (Borja \& Ostrosky, 2013; Campbell, Porter, \& Santor, 2004; Poythress et al., 2006). Thus, some researchers have argued that the more primary elements of psychopathy are important, which is not identified by the experts, who appear to favour secondary psychopathy components as likely influenced. There was, however, some consistency in opinion between the Delphi and prior research concerning multiple trauma exposure as important in psychopathy development (e.g. Schimmenti et al., 2014), with this further supported by the findings of the 
systematic review. Thus, there was consistency in opinion between these two studies. This offered some support for the prediction that different types of trauma would be associated with different subtypes of psychopathy, both secondary and primary psychopathy.

However, trauma type was not found to differentiate between those with or without psychopathy, or the related concept of Antisocial Personality Disorder (APD), when considering patient history using a file trawl. This suggested that the prediction was not reliably supported. However, it did appear more important to account for trauma severity, with the final study demonstrating how severity of trauma type was shown to be a significant predictor for psychopathy subtypes. This applied to physical trauma severity, with increased levels predicting both primary and secondary psychopathy, and overall (increased) trauma severity predicting secondary psychopathy. Thus, there was some support for the prediction that the severity of trauma would be associated with higher levels of psychopathy, but this only related to the more impulsive and emotionally unstable component, secondary psychopathy, with primary (and secondary) predicted only by physical trauma severity. Although the prediction was not therefore completely supported it does highlight how severity of trauma, not just its experience, is an important factor in relation to some elements of psychopathy and how it may be specific elements of trauma severity that are particularly key, namely physical. This also shared some similarities with Kolla et al., (2013) who reported how severe physical abuse was associated more with reactive aggression, when PCL-R scores were also raised. Reactive aggression is, as indicated, more aligned with secondary psychopathy.

The association between physical abuse severity and primary psychopathy is worthy of note. Primary psychopathy explanations can often overlook the role of the environment, focusing more on the hereditary and genetic components to psychopathic personality (Blair, 2003, 2006; Kiehl et al., 2001; Skeem et al., 2007), which some may argue is reductionist. Therefore, the current research finding that physical trauma severity was a strong predictor for not only secondary 
but also primary psychopathy is notable, as it suggests a possible environmental role for primary psychopathy development. This is not frequently described in current literature and therefore requires further exploration. The current study lends support to a more complex relationship between psychopathy and trauma that is beginning to emerge, one that accounts for psychopathy type. It could also be speculated that the more severe physical abuse experienced by the high secure patient sample could have different effects on the psychopathy subtypes, acting to increase both via different mechanisms. For example, it could be speculated that those with primary psychopathy may have already begun to exhibit differences in temperament in childhood, such as CU traits and fearlessness, due to the genetic components of primary psychopathy traits already being present (Blair et al., 2006; Lykken, 1995; Porter, 1996; Yildrim \& Derksen, 2015). Presence of $\mathrm{CU}$ traits in childhood can lead to more negative and inconsistent parenting practices (Edens, Skopp \& Cahill, 2008), with such negative parenting practices arguably including more severe physical abuse and serving to make a child less emotionally responsive (D'Andrea et al., 2012), thereby exacerbating their biological primary psychopathy traits. Severe physical abuse can also lead to increased reactive aggression, difficulties with emotional regulation and impulsive antisocial behaviour (D’Andrea et al., 2012; Farrington, 2005; Kolla et al., 2013; Ties1 \& Cichetti, 2008), which relate more to secondary psychopathy traits. This implies that severe physical trauma may be acting to exacerbate hereditary primary psychopathy traits and influence the emergence of secondary psychopathy traits, by way of different mechanisms. Such reasoning is supported by the current findings, whereby a positive association was found between physical trauma severity and both factor one and two scores.

Trust development, or lack of, appeared worthy of acknowledgement, a finding consistent with the literature (Pittman, Keiley, Kerpelman \& Vaughn, 2011). A lack of trust formation due to developmental trauma was agreed to affect the possibility of psychopathy emergence by the majority of the Delphi expert sample. It also links to attachment, with trust and the need to preserve 
this, arguably forming a fundamental component (Freyd, 1994). Attachment is vital for the development of future social bonds and relationships and was identified as a factor linked to the psychopathy and trauma relationship in the systematic review. It could be speculated, on this basis, that it is the combination of challenges in attachment (Schimmenti et al., 2014) and absence of trust development that may contribute to raised levels of psychopathy and other challenges, such as conduct problems, aggression and delinquency (Eliot \& Cornell, 2009; Hoeve, Stams, van der Put, Dubas, van der Laan \& Gerris, 2012); all of which are associated with psychopathy (Kimonis et al., 2013; Kolla et al., 2013; Pechorro, Maroco, Gonçalves, Nunes \& Jesus, 2014; Werner, Few \& Bucholz, 2015).

Whilst this research has generated interesting findings, there are limitations, which must be acknowledged. Regarding the Delphi, the main limitation was the presence of some misunderstanding of concepts, for example secondary psychopathy, which may have impacted on the interpretation of statements and resulting agreement levels. However, if experts did disagree they could comment stating why and provide additional information. Additionally, the patient file trawl comprised a small sample, with personality assessments completed by a range of professionals, meaning the quality of these could not be ensured and reliability could not be checked. However, all were completed by qualified professionals, either psychologists or psychiatrists. Furthermore, even though research in this area is sparse involving high secure male patients, making the current findings an important contribution to research, the findings are difficult to generalise to other populations. In addition, there was a need to incorporate raised consideration of other important factors, such as dissociation as an experienced symptom set, accounting for the extent to which betrayal trauma was considered important across studies (Sivers et al, 2002). The study is unable to account, therefore, for a potential role of dissociative symptoms in the trauma-psychopathy relationship and whether there is a differing relationship, or not, with psychopathy. Finally, there is certainly a need to utilise longitudinal research designs so that the 
developmental trajectory from trauma exposure to unhelpful personality traits, such as psychopathy, can be considered in more detail; such research is not impossible to complete but it does present with challenges relating to the resources required and the ethics of engaging those who are exposed to trauma and how they are consequently safeguarded.

Overall, there was consensus across the studies concerning an association between psychopathy and trauma, with betrayal trauma/trust appearing core concepts of value. There was also agreement across the studies on multiple traumatic experiences being important, although trauma type was not key in the patient study. Here, trauma severity appeared more important, notably for secondary psychopathy, and only in relation to physical trauma for primary. This apparent focus on secondary psychopathy was also aligned to the expert Delphi sample, who seemed to focus more on this component of psychopathy as being key, a feature not identified in the systematic review, where both primary and secondary was accounted for. Thus, across studies, there was agreement on betrayal trauma, the nature of reported trauma, and components of psychopathy as key considerations, with the core difference appearing a focus more on secondary psychopathy by the expert sample.

Despite some consensus concerning a conceptual and proven association between psychopathy and trauma, the mechanism by which this association occurs, and its strength, requires further examination. We can conclude that the nature and severity of trauma are important considerations, as is the need to capture psychopathy as a heterogeneous concept. Making global statements regarding psychopathy and trauma being associated fails to account, however, for the importance of attending to the components of psychopathy, type of trauma and trauma severity. In the absence of longitudinal studies and those that account for trauma diagnoses as opposed to symptoms, the research area may not progress beyond correlational findings and speculation. Regardless, the current series of studies have demonstrated how this is an area worthy of further study. They also highlight an important omission from the literature, that of diversity-related 
factors being considered. Although sex is captured, it is only to a minimal degree in the systematic review. It is further clear that the research area has primarily neglected race, culture and ethnicity, for example. It is true to note that most of the research on psychopathy or antisocial behaviour is on men, with trauma connected to childhood experiences primarily focusing on women. There is a need therefore to research sex equally across the area of psychopathy and trauma and to expand it to cover other diversity-related factors, such as race, culture and ethnicity. Future research needs to attend to these important issues of inclusion. Such research should also be directed to attending more closely to the vulnerabilities in developmental background to those who present with psychopathy and/or psychopathic traits, including across a wider range of populations. It could consider factors that may correlate with and/or drive enduring trauma experiences, such as dissociation. Expanding consideration to how adverse childhood experiences promote the development of psychopathy in some instances would have considerable value. This should include consideration of what factors, such as resilience components, reduce the potential for challenging personality from developing. This is a clear direction for longitudinal research to consider.

\section{References}

Ainsworth, M. D. S., Bieha M. C., Waters, E., \& Wall, S. (1978). Patterns of attachment: A psychological study of the strange situation. Hillsdale, N J: Erlhaum.

Ainsworth, M. S. (1979). Infant-mother attachment. American Psychologist, 34(10), 932. doi:10.1037/0003-066x.34.10.932

Ainsworth, M. S. (1989). Attachments beyond infancy. American Psychologist, 44(4), 709. doi:10.1037/0003-066x.44.4.709

Alisic, E., Jongmans, M. J., van Wesel, F., \& Kleber, R. J. (2011). Building child trauma theory from longitudinal studies: A meta-analysis. Clinical Psychology Review, 31(5), 736-747. doi:10.1016/j.cpr.2011.03.001 
American Psychiatric Association (2013). Diagnostic and statistical manual of mental disorders $\left(5^{\text {th }} \quad\right.$ ed.) Arlington, VA: American Psychiatric Publishing. doi:10.1176/appi.books.9780890425596

American Psychological Association (2016). Retrieved from http://www.apa.org/topics/trauma/ on $11^{\text {th }}$ August 2016.

Anderson, N. E., \& Kiehl, K. A. (2014). Psychopathy: developmental perspectives and their implications for treatment. Restorative Neurology and Neuroscience, 32(1), 103-117.

Andrade, J. T. (2010). Psychosocial precursors of psychopathy in a psychiatric sample: A structural equation model analysis. Dissertation Abstracts International Section A, 71, 712.

Atchinson, B. J., \& Morkut, B. (2011). Developmental Trauma Disorder. In B. J. Atchinson \& D. K. Dirette (Eds.) Conditions in Occupational Therapy, (pp.323-336). Baltimore, MD: Lippincott Williams \& Wilkins.

Bailey, C., \& Shelton, D. (2014). Self-reports of faulty parental attachments in childhood and criminal psychopathy in an adult-incarcerated population: an integrative literature review. Journal Of Psychiatric \& Mental Health Nursing, 21(4), 365-374 10p. doi:10.1111/jpm.12086

Baskerville, R., \& Pries-Heje, J. (1999). Grounded action research: a method for understanding IT in practice. Accounting, Management and Information Technologies, 9(1), 1-23. doi:10.1016/s0959-8022(98)00017-4

Bayliss, C. M., Miller, A. K., \& Henderson, C. E. (2010). Psychopathy development and implications for early intervention. Journal of Cognitive Psychotherapy, 24(2), 71-80. doi:10.1891/0889-8391.24.2.71

Bernstein, D. P., Ahluvalia, T., Pogge, D., \& Handelsman, L. (1997). Validity of the Childhood Trauma Questionnaire in an adolescent psychiatric population. Journal of the American Academy of Child \& Adolescent Psychiatry, 36(3), 340-348. doi:10.1097/00004583199703000-00012 
Bernstein, D. P., Fink, L., Handelsman, L., Foote, J., Lovejoy, M., Wenzel, K., Sapareto, E., \& J. Ruggiero, J. (1994). Initial reliability and validity of a new retrospective measure of child abuse and neglect. American Journal of Psychiatry, 151, 1132-1136. doi:10.1176/ajp.151.8.1132

Blackburn, R., \& Coid, J. W. (1999). Empirical clusters of DSM-III personality disorders in violent offenders. Journal of Personality Disorders, 13(1), 18-34. doi:10.1521/pedi.1999.13.1.18

Blackburn, R., Logan, C., Donnelly, J. P., \& Renwick, S. J. (2008). Identifying psychopathic subtypes: Combining an empirical personality classification of offenders with the Psychopathy Checklist-Revised. Journal of Personality Disorders, 22(6), 604-622. doi:10.1521/pedi.2008.22.6.604

Blair, R. J. R. (2003). Neurobiological basis of psychopathy. The British Journal of Psychiatry, 182(1), 5-7. doi:10.1192/bjp.182.1.5

Blair, R. J. R., Peschardt, K. S., Budhani, S., Mitchell, D. G. V., \& Pine, D. S. (2006). The development of psychopathy. Journal of Child Psychology and Psychiatry, 47(3-4), 262-276. doi:10.1111/j.1469-7610.2006.01596.x

Blonigen, D. M., Sullivan, E. A., Hicks, B. M., \& Patrick, C. J. (2012). Facets of psychopathy in relation to potentially traumatic events and posttraumatic stress disorder among female prisoners: The mediating role of borderline personality disorder traits. Personality Disorders: Theory, Research, and Treatment, 3(4), 406. doi:10.1037/a0026184

Borja, K., \& Ostrosky, F. (2013). Early traumatic events in psychopaths. Journal of Forensic Sciences, 58(4), 927-931. doi:10.1111/1556-4029.12104

Braun, V., \& Clarke, V. (2006) Using thematic analysis in psychology. Qualitative Research in Psychology, 3(2). pp. 77-101. ISSN 1478-0887 Available from: http://eprints.uwe.ac.uk/11735

Brinkley, C. A., Schmitt, W. A., Smith, S. S., \& Newman, J. P. (2001). Construct validation of a self-report psychopathy scale: Does Levenson's self-report psychopathy scale measure the 
same construct as Hare's psychopathy checklist - Revised? Personality and Individual Differences, 31, 1021-1038. doi:10.1016/s0191-8869(00)00178-1

Bruce, M., \& Laporte, D. (2015). Childhood trauma, antisocial personality typologies and recent violent acts among inpatient males with severe mental illness: Exploring an explanatory pathway. Schizophrenia Research, 162(1), 285-290. doi:10.1016/j.schres.2014.12.028

Campbell, M. A., Porter, S., \& Santor, D. (2004). Psychopathic traits in adolescent offenders: an evaluation of criminal history, clinical, and psychosocial correlates. Behavioural Sciences \& the Law, 22(1), 23-47. doi:10.1002/bsl.572

Christopher, K., Lutz-Zois, C. J., \& Reinhardt, A. R. (2007). Female sexual-offenders: personality pathology as a mediator of the relationship between childhood sexual abuse history and sexual abuse perpetration against others. Child Abuse \& Neglect, 31(8), 871-883.

Cicchetti, D., \& Toth, S. L. (2005). Child maltreatment. Annual Review of Clinical Psychology, 1(1), 409-438. doi:10.1146/annurev.clinpsy.1.102803.144029

Cicchetti, D., \& Valentino, K. (2006). An ecological-transactional perspective on child maltreatment: Failure of the average expectable environment and its influence on child development. Developmental Psychopathology, Second Edition, 129-201. doi:10.1002/9780470939406.ch4

Cima, M., Smeets, T., \& Jelicic, M. (2008). Self-reported trauma, cortisol levels, and aggression in psychopathic and non-psychopathic prison inmates. Biological Psychology, 78(1), 75-86. doi:10.1016/j.biopsycho.2007.12.011

Cleckley, H. (1982). The mask of sanity (rev ed.). St. Louis, Missouri: The C. V. Mosby

Cleckley, H.M. (1988). The mask of sanity: An attempt to clarify some issues about the so called psychopathic personality (5th ed.). Augusta: Emily S. Cleckley. doi:10.1037/11395-000

Cohen, J., (1988). Statistical power analysis for the behavioural sciences. New Jersey: Lawrence Erlbaum Associates Inc. Publishers. 
Coid, J., \& Ullrich, S. (2010). Antisocial personality disorder is on a continuum with psychopathy. Comprehensive Psychiatry, 51(4), 426-433. doi:10.1016/j.comppsych.2009.09.006

Coid, J., \& Yang, M. (2011). The impact of psychopathy on violence among the household population of Great Britain. Social Psychiatry and Psychiatric Epidemiology, 46(6), 473-480. doi:10.1007/s00127-010-0212-4

Coid, J., Yang, M., Ullrich, S., Roberts, A., \& Hare, R. D. (2009). Prevalence and correlates of psychopathic traits in the household population of Great Britain. International Journal of Law and Psychiatry, 32(2), 65-73. doi:10.1016/j.ijlp.2009.01.002

Coid, J., Yang, M., Ullrich, S., Roberts, A., Moran, P., Bebbington, P., .. \& Singleton, N. (2009). Psychopathy among prisoners in England and Wales. International Journal of Law and Psychiatry, 32(3), 134-141. doi:10.1016/j.ijlp.2009.02.008

Courtois, C. A. (2004). Complex trauma, complex reactions: Assessment and treatment. Psychotherapy: Theory, Research, Practice, Training,41(4), 412-425. doi:10.1037/0033-3204.41.4.412

D’Andrea, W., Ford, J., Stolbach, B., Spinazzola, J., \& van der Kolk, B. A. (2012). Understanding interpersonal trauma in children: why we need a developmentally appropriate trauma diagnosis. American Journal of Orthopsychiatry, 82(2), 187-200. doi:10.1111/j.19390025.2012.01154.x

Dargis, M., Newman, J., \& Koenigs, M. (2016). Clarifying the link between childhood abuse history and psychopathic traits in adult criminal offenders. Personality Disorders: Theory, Research, and Treatment, 7(3), 221-228. doi:10.1037/per0000147

DeLisi, M. (2016). Psychopathy as Unified Theory of Crime. Palgrave Macmillan, New York.

DeLisi, M. (2009). Psychopathy is the unified theory of crime. Youth Violence and Juvenile Justice, 7, 256. 
Douglas, K. S., Ogloff, J. R., Nicholls, T. L., \& Grant, I. (1999). Assessing risk for violence among psychiatric patients: the HCR-20 violence risk assessment scheme and the Psychopathy Checklist: Screening Version. Journal of Consulting and Clinical Psychology, 67(6), 917. doi:10.1037/0022-006x.67.6.917

Douglas, K. S., Vincent, G. M., \& Edens, J. F. (2006). Risk for criminal recidivism: The role of psychopathy. In C.J. Patrick (Ed.), Handbook of Psychopathy, (pp. 533-554). Guilford Press: New York.

Edens, J. F., Skopp, N. A., \& Cahill, M. A. (2008). Psychopathic features moderate the relationship between harsh and inconsistent parental discipline and adolescent antisocial behaviour. Journal of Clinical Child \& Adolescent Psychology, 37(2), 472-476. doi:10.1080/15374410801955938

Edwards, J. D. (2013). Juvenile psychopathy and traumatic events among incarcerated adolescents. Dissertation Abstracts International, 74.

Eliot, M., \& Cornell, D. G. (2009). Bullying in middle school as a function of insecure attachment and aggressive attitudes. School Psychology International, 30(2), 201-214. doi:10.1177/0143034309104148

English, D. J. \& the LONGSCAN Investigators (1997). Modified Maltreatment Classification System (MMCS).

Falkenbach, D. M., Stern, S. B., \& Creevy, C. (2014). Psychopathy variants: Empirical evidence supporting a subtyping model in a community sample. Personality Disorders: Theory, Research, and Treatment, 5(1), 10. doi:10.1037/per0000021

Farrington, D. P. (2005). Childhood origins of antisocial behaviour. Clinical Psychology \& Psychotherapy, 12(3), 177-190. doi:10.1002/cpp.448

Faul, F., Erdfelder, E., Buchner, A., \& Lang, A.-G. (2009). Statistical power analyses using G*Power 3.1: Tests for correlation and regression analyses. Behaviour Research Methods, 41, 1149-1160. doi:10.3758/brm.41.4.1149 
Fingerson, S. H. (2008). The relationships among trauma, dissociation and psychopathy in women. Dissertation Abstracts International, 68, 5567.

Fisher, A. G. (2004). The relationship of psychopathy and abuse victimization to level of juvenile sexually problematic behavior. Dissertation Abstracts International, 64, 6326.

Freyd, J. (1994). Betrayal trauma: Traumatic amnesia as an adaptive response to childhood abuse. Ethics \& Behaviour, 4(4), 307-329. doi:10.1207/s15327019eb0404_1

Frick, P. J., \& Marsee, M. A., (2006). Psychopathy and developmental pathways to antisocial behaviour in youth. In C. J., Patrick (Ed.), Handbook of Psychopathy, (pp. 353-374). Guildford Press: New York.

Frick, P. J., Kimonis, E. R., Dandreaux, D. M., \& Farell, J. M. (2003). The 4 year stability of psychopathic traits in non-referred youth. Behavioural Sciences \& the Law, 21(6), 713-736. doi:10.1002/bsl.568

Frodi, A., Dernevik, M., Sepa, A., Philipson, J., \& Bragesjö, M. (2001). Current attachment representations of incarcerated offenders varying in degree of psychopathy. Attachment \& Human Development, 3(3), 269-283. doi:10.1080/14616730110096889

Galietta, M., \& Rosenfeld, B. (2012). Adapting Dialectical Behavior Therapy (DBT) for the treatment of psychopathy. The International Journal Of Forensic Mental Health, 11(4), 325335. doi:10.1080/14999013.2012.746762

Gao, Y., Raine, A., Chan, F., Venables, P. H., \& Mednick, S. A. (2010). Early maternal and paternal bonding, childhood physical abuse and adult psychopathic personality. Psychological Medicine, 40(6), 1007-1016. doi:10.1017/S0033291709991279

Graham, N., Kimonis, E. R.., Wasserman, A. L., \& Kline, S. M. (2012). Associations among childhood abuse and psychopathy facets in male sexual offenders. Personality Disorders: Theory, Research, and Treatment, 3(1), 66-75. doi:10.1037/a0025605 
Groh, A. M., Fearon, R. P., Bakermans-Kranenburg, M. J., Van Ijzendoorn, M. H., Steele, R. D., \& Roisman, G. I. (2014). The significance of attachment security for children's social competence with peers: A meta-analytic study. Attachment \& Human Development, 16(2), 103-136. doi:10.1080/14616734.2014.883636

Guay, J. P., Ruscio, J., Knight, R. A., Hare, R. D. (2007). A taxometric analysis of the latent structure of psychopathy: evidence for dimensionality. Journal of Abnormal Psychology, 116, 701-716. doi:10.1037/0021-843x.116.4.701

Hamilton, R. K., Hiatt Racer, K., \& Newman, J. P. (2015). Impaired integration in psychopathy: A unified theory of psychopathic dysfunction. Psychological Review, 122(4), 770. doi:10.1037/a0039703

Hare, R. D. (2003). The Psychopathy Checklist Revised. Toronto, ON: Multi-Health Systems.

Hare, R. D., \& Neumann, C. S. (2005). Structural models of psychopathy. Current Psychiatry Reports, 7(1), 57-64. doi:10.1007/s11920-005-0026-3

Hare, R. D., \& Neumann, C. S. (2008). Psychopathy as a clinical and empirical construct. Annual Review of Clinical Psychology, 4, 217-246. doi:10.1146/annurev.clinpsy.3.022806.091452

Hare, R.D. (1980). A research scale for the assessment of psychopathy in criminal populations. Personality and Individual Differences, 1, 111-119. doi:10.1016/0191-8869(80)90028-8

Hare, R.D. (1991). The Hare Psychopathy Checklist Revised. Toronto, ON: Multi-Health Systems. doi:10.1037/t04993-000

Harris, G. T., Rice, M. E., \& Lalumière, M. (2001). Criminal violence: The roles of psychopathy, neurodevelopmental insults, and antisocial parenting. Criminal Justice and Behaviour, 28(4), 402-426. doi:10.1177/009385480102800402

Hart, S. D., \& Hare, R. D. (1996). Psychopathy and risk assessment. Current Opinion in Psychiatry, 9(6), 380-383. doi:10.1097/00001504-199611000-00002 
Hermann, H. R. (2017). 'Alternate Human Behavior' in Hermann, H. R., Dominance and Aggression in Humans and Other Animals: The Great Game of Life (pp. 139 - 157). Academic Press: Elsevier.

Hicks, B. M., Markon, K. E., Patrick, C. J., Krueger, R. F., \& Newman, J. P. (2004). Identifying psychopathy subtypes on the basis of personality structure. Psychological Assessment, 16(3), 276. doi:10.1037/1040-3590.16.3.276

Hicks, B. M., Vaidyanathan, U., \& Patrick, C. J. (2010). Validating female psychopathy subtypes: differences in personality, antisocial and violent behaviour, substance abuse, trauma, and mental health. Personality Disorders: Theory, Research, and Treatment, 1(1), 38. doi:10.1037/a0018135

Hildebrand, M., \& de Ruiter, C. (2004). PCL-R psychopathy and its relation to DSM-IV Axis I and II disorders in a sample of male forensic psychiatric patients in the Netherlands. International Journal of Law and Psychiatry, 27(3), 233-248. doi:10.1016/j.ijlp.2004.03.005

Hoeve, M., Stams, G. J. J., van der Put, C. E., Dubas, J. S., van der Laan, P. H., \& Gerris, J. R. (2012). A meta-analysis of attachment to parents and delinquency. Journal of Abnormal Child Psychology, 40(5), 771-785. doi:10.1007/s10802-011-9608-1

Hsu, C. C., \& Sandford, B. A. (2007). The Delphi technique: making sense of consensus. Practical Assessment, Research \& Evaluation, 12(10), 1-8.

ICD, W. H. O. (1992). 10: International statistical classification of diseases and related health problems. World Health Organization, Geneva, b10.

Karpman, B. (1941). On the need of separating psychopathy into two distinct clinical types: the symptomatic and the idiopathic. Journal of Criminal Psychopathology, 3, 112-137.

Kerig, P. K., \& Becker, S. P. (2010). From internalizing to externalizing: Theoretical models of the processes linking PTSD to juvenile delinquency. In S. J. Egan (Ed.), PTSD: Causes, symptoms and treatment (pp. 33-78). Hauppauge, NY: Nova. 
Kerig, P. K., \& Becker, S. P. (2015). Early abuse and neglect as risk factors for the development of criminal and antisocial behaviour. In J. Morizot, \& L. Kazemian (Eds.) The Development of Criminal and Antisocial Behaviour(pp. 181-199). Springer International Publishing. doi:10.1007/978-3-319-08720-7_12

Kerig, P. K., Bennett, D. C., Thompson, M., \& Becker, S. P. (2012). "Nothing really matters": Emotional numbing as a link between trauma exposure and callousness in delinquent youth. Journal of Traumatic Stress, 25(3), 272-279. doi: 10.1002/jts.21700

Kerig, P. K., Bennett, D. C., Thompson, M., \& Becker, S. P. (2012). Nothing really matters: emotional numbing as a link between trauma exposure and callousness in delinquent youth. Journal of Traumatic Stress, 25, 272-279. http://dx.doi.org/10.1002/jts.21700.

Kiehl, K. A. (2006). A cognitive neuroscience perspective on psychopathy: Evidence for paralimbic system dysfunction. Psychiatry Research, 142(2), 107-128. doi:10.1016/j.psychres.2005.09.013

Kiehl, K. A., \& Hoffman, M. B. (2011). The criminal psychopath: history, neuroscience, treatment, and economics. Jurimetrics, 51, 355-397.

Kiehl, K. A., Smith, A. M., Hare, R. D., Forster, B. B., Brink, J., \& Liddle, P. F. (2001). Limbic abnormalities in affective processing by criminal psychopaths as revealed by functional magnetic resonance imaging. Biological Psychiatry, 50, 677-684. doi:10.1016/s0006$3223(01) 01222-7$

Kimonis, E. R., Fanti, K. A., Isoma, Z., \& Donoghue, K. (2013). Maltreatment profiles among incarcerated boys with callous-unemotional traits. Child Maltreatment, 18(2), 108-121. doi:10.1177/1077559513483002

Kimonis, E. R., Frick, P. J., Cauffman, E., Goldweber, A., \& Skeem, J. (2012). Primary and secondary variants of juvenile psychopathy differ in emotional processing. Development and Psychopathology, 24(03), 1091-1103. doi:10.1017/s0954579412000557 
Kimonis, E. R., Skeem, J. L., Cauffman, E., \& Dmitrieva, J. (2011). Are secondary variants of juvenile psychopathy more reactively violent and less psychosocially mature than primary variants? Law And Human Behavior, 35(5), 381-391. doi:10.1007/s10979-010-9243-3

Kolla, N. J., Gregory, S., Attard, S., Blackwood, N., \& Hodgins, S. (2014). Disentangling possible effects of childhood physical abuse on gray matter changes in violent offenders with psychopathy. Psychiatry Research: Neuroimaging, 221(2), 123-126. doi:10.1016/j.pscychresns.2013.11.008

Kolla, N. J., Malcolm, C., Attard, S., Arenovich, T., Blackwood, N., \& Hodgins, S. (2013). Childhood maltreatment and aggressive behaviour in violent offenders with psychopathy. The Canadian Journal of Psychiatry, 58(8), 487-494. doi:10.1177/070674371305800808

Krischer, M. K., \& Sevecke, K. (2008). Early traumatization and psychopathy in female and male juvenile offenders. International Journal of Law and Psychiatry, 31(3), 253-262. doi:10.1016/j.ijlp.2008.04.008

Kristic, S., Knight, R. A., \& Robertson, C. A. (2016). Developmental antecedents of the facets of psychopathy: the role of multiple abuse experiences. Journal of Personality Disorders, 30(5), 677-693. doi:10.1521/pedi_2015_29_223

Lang, S., Af Klinteberg, B., \& Alm, P. O. (2002). Adult psychopathy and violent behaviour in males with early neglect and abuse. Acta Psychiatrica Scandinavica, 106(s412), 93-100. doi:10.1034/j.1600-0447.106.s412.20.x

Lansford, J. E., Dodge, K. A., Pettit, G. S., Bates, J. E., Crozier, J., \& Kaplow, J. (2002). A 12-year prospective study of the long-term effects of early child physical maltreatment on psychological, behavioural, and academic problems in adolescence. Archives of Pediatrics \& Adolescent Medicine, 156(8), 824-830. doi:10.1001/archpedi.156.8.824

Leach, G., \& Meloy, J. R. (1999). Serial murder of six victims by an African-American male. Journal of Forensic Sciences, 44(5), 1073-1078. 
Lewis, M., Ireland, J. L., Abbott, J., \& Ireland, C. A. (2017). Initial development of the psychopathic processing and personality assessment (PAPA) across populations. International Journal of Law and Psychiatry, doi:10.1016/j.ijlp.2017.06.006

Linden, S. C., Hess, V., \& Jones, E. (2012). The manifestations of trauma: lessons from World War I. European Archives of Psychiatry and Clinical Neuroscience, 262(3), 253-264. doi:10.1007/s00406-011-0272-9

Loeber, R., Burke, J. D., \& Lahey, B. B. (2002). What are adolescent antecedents to antisocial personality disorder? Criminal Behaviour and Mental Health, 12(1), 24-36. doi:10.1002/cbm.484

Lykken, D. T. (1995). The antisocial personalities. Psychology Press. doi:10.4324/9780203763551

Marshall, L. A., \& Cooke, D. J. (1999). The childhood experiences of psychopaths: A retrospective study of familial and societal factors. Journal of Personality Disorders, 13(3), 211-225. doi:10.1521/pedi.1999.13.3.211

Moore, R. L. (2005). The association between psychopathy and autonomic reactivity in young adolescents. Dissertation Abstracts International, 65, 6702.

Murray, J., \& Farrington, D. P. (2010). Risk factors for conduct disorder and delinquency: key findings from longitudinal studies. The Canadian Journal of Psychiatry, 55(10), 633-642. doi:10.1177/070674371005501003

National Children's Traumatic Stress Network (2003). Complex trauma in children and adolescents. Retrieved from:

http://www.nctsnet.org/nctsn_assets/pdfs/edu_materials/ComplexTrauma_All.pdf

Neumann, C. S., Hare, R. D., \& Newman, J. P. (2007). The super-ordinate nature of the Psychopathy Checklist-Revised. Journal of Personality Disorders, 21(2), 102-117. doi:10.1521/pedi.2007.21.2.102 
Neumann, C. S., Hare, R. D., \& Pardini, D. A. (2015). Antisociality and the construct of psychopathy: Data from across the globe. Journal of Personality, 83(6), 678-692. doi:10.1111/jopy.12127

Nørbech, P. B., Crittenden, P. M., \& Hartmann, E. (2013). Self-protective strategies, violence and psychopathy: Theory and a case study. Journal of Personality Assessment, 95(6), 571-584. doi:10.1080/00223891.2013.823441

Norman, R. E., Byambaa, M., De, R., Butchart, A., Scott, J., \& Vos, T. (2012). The long-term health consequences of child physical abuse, emotional abuse, and neglect: a systematic review and meta-analysis. PLoS Medicine, 9(11), e1001349. doi:10.1371/journal.pmed.1001349

Ogloff, J. R. (2006). Psychopathy/antisocial personality disorder conundrum. Australian and New Zealand Journal of Psychiatry, 40(6), 519-528. doi:10.1111/j.1440-1614.2006.01834.x

Ogloff, J. R., Campbell., R. E., \& Shepherd, S. M (2016). Disentangling psychopathy from Antisocial Personality Disorder: An Australian analysis. Journal of Forensic Psychology Practice. 16 (3), $198-215$.

O'Neill, M. L., Lidz, V., \& Heilbrun, K. (2003). Predictors and correlates of psychopathic characteristics in substance abusing adolescents. The International Journal Of Forensic Mental Health, 2(1), 35-46.

Päivärinta, T., Pekkola, S., \& Moe, C. (2011). Grounding theory from Delphi studies. Research Methods and Philosophy. Thirty second annual conference on Information Systems, Shanghai. Parenté, F. J., Anderson, J. K., Myers, P., \& O’Brien, T. (1984). An examination of factors contributing to Delphi accuracy. Journal of Forecasting, 3(2), 173-182. doi:10.1002/for.3980030205

Pasold, T. L. (2007). Understanding the transgenerational cycle of parenting: The role of past parenting experiences and emotional functioning. Dissertation Abstracts International, 68, 631. 
Pechorro, P., Maroco, J., Gonçalves, R. A., Nunes, C., \& Jesus, S. N. (2014). Psychopathic traits and age of crime onset in male juvenile delinquents. European Journal of Criminology, 11(3), 288-302. doi:10.1177/1477370813495759

Piquero, A. R., Farrington, D. P., Fontaine, N. M., Vincent, G., Coid, J., \& Ullrich, S. (2012). Childhood risk, offending trajectories, and psychopathy at age 48 years in the Cambridge Study in Delinquent Development. Psychology, Public Policy, and Law, 18(4), 577. doi:10.1037/a0027061

Pittman, J. F., Keiley, M. K., Kerpelman, J. L., \& Vaughn, B. E. (2011). Attachment, identity, and intimacy: Parallels between Bowlby's and Erikson's paradigms. Journal of Family Theory \& Review, 3(1), 32-46.

Porter, S. (1996). Without conscience or without active conscience? The aetiology of psychopathy revisited. Aggression and Violent Behaviour, 1(2), 179-189. doi:10.1016/13591789(95)00010-0

Poythress, N. G., Skeem, J. L., \& Lilienfeld, S. O. (2006). Associations among early abuse, dissociation, and psychopathy in an offender sample. Journal of Abnormal Psychology, 115(2), 288-297. doi:10.1037/0021-843x.115.2.288

Prisma (2009a). Prisma 2009 Flow Diagram. Retrieved from http://prismastatement.org/documents/PRISMA\%202009\%20flow\%20diagram.pdf

Prisma (2009b). Prisma 2009 Checklist. Retrieved from http://prismastatement.org/documents/PRISMA\%202009\%20checklist.pdfhttp://prismastatement.org/documents/PRISMA 2009 checklist.pdf

Radford, L. et al. (2011) Child abuse and neglect in the UK today. London: NSPCC.

Rodríguez-Mañas, L., Féart, C., Mann, G., Viña, J., Chatterji, S., Chodzko-Zajko, W., ... \& Scuteri, A. (2013). Searching for an operational definition of frailty: a Delphi method based consensus 
statement. The frailty operative definition-consensus conference project. The Journals of Gerontology: Series A, 68(1), 62-67. doi:10.1093/gerona/gls119

Sar, V. (2011). Developmental trauma, complex PTSD and the current proposal of DSM5. European Journal of Psychotraumatology, 2. doi:10.3402/ejpt.v2i0.5622

Sarkar, S., Clark, B. S., \& Deeley, Q. (2011). Differences between psychopathy and other personality disorders: Evidence from neuroimaging. Advances in Psychiatric Treatment, 17 (3), 191 - 200. https://doi.org/10.1192/apt.bp.107.004747

Schember, J. J. (2008). Trauma and coping in juvenile delinquents. Dissertation Abstracts International, 68, 6335.

Schimmenti, A., Di Carlo, G., Passanisi, A., \& Caretti, V. (2015). Abuse in childhood and psychopathic traits in a sample of violent offenders. Psychological Trauma: Theory, Research, Practice, and Policy, 7(4), 340-347. doi:10.1037/tra0000023

Schimmenti, A., Passanisi, A., Pace, U., Manzella, S., Di Carlo, G., \& Caretti, V. (2014). The relationship between attachment and psychopathy: a study with a sample of violent offenders. Current Psychology, 33(3), 256-270. doi:10.1007/s12144-014-9211-z

Serin, R. C. (1991). Psychopathy and violence in criminals. Journal of Interpersonal Violence, 6(4), 423-431. doi:10.1177/088626091006004002

Shields, A., \& Cicchetti, D. (1998). Reactive aggression among maltreated children: The contributions of attention and emotion dysregulation. Journal of Clinical Child Psychology, 27(4), 381-395. doi:10.1207/s15374424jccp2704_2

Sivers, H., Schooler, J., Freyd, J. L. (2002). 'Recovered Memories' in V. S. Ramachandran (Ed.) Encyclopedia of the Human Brain, V4 (169 - 184), Academic Press: US and London.

Skeem, J., Johansson, P., Andershed, H., Kerr, M., \& Louden, J. E. (2007). Two subtypes of psychopathic violent offenders that parallel primary and secondary variants. Journal of Abnormal Psychology, 116(2), 395. doi:10.1037/0021-843x.116.2.395 
Sousa, C., Herrenkohl, T. I., Moylan, C. A., Tajima, E. A., Klika, J. B., Herrenkohl, R. C., \& Russo, M. J. (2011). Longitudinal study on the effects of child abuse and children's exposure to domestic violence, parent-child attachments, and antisocial behaviour in adolescence. Journal of Interpersonal Violence, 26(1), 111-136. doi.org/10.1177/0886260510362883

Sperry, D. M., \& Gilbert, B. O. (2005). Child peer sexual abuse: Preliminary data on outcomes and disclosure experiences. Child Abuse and Neglect, 29(8), 889-904. doi:10.1016/j.chiabu.2004.12.011

Stevenson, L. N. (2010). Family environment, child abuse, and neurological injury as predictors of psychopathy in insanity acquittees. Dissertation Abstracts International, 70, 5884.

Tatar, J. R., Cauffman, E., Kimonis, E. R., \& Skeem, J. L. (2012). Victimization history and posttraumatic stress: An analysis of psychopathy variants in male juvenile offenders. Journal of Child \& Adolescent Trauma, 5(2), 102-113. doi:10.1080/19361521.2012.671794

Teisl, M., \& Cicchetti, D. (2008). Physical abuse, cognitive and emotional processes, and aggressive/disruptive behaviour problems. Social Development, 17(1), 1-23. doi:10.1111/j.1467-9507.2007.00412.x

Ullrich, S., \& Marneros, A. (2007). Underlying dimensions of ICD-10 personality disorders: Risk factors, childhood antecedents, and adverse outcomes in adulthood. Journal Of Forensic Psychiatry \& Psychology, 18(1), 44-58. doi:10.1080/14789940601014769

Valentine, I. S. (2001, April). The relationship between depression, self-esteem, trauma, and psychopathy in understanding conduct disordered adolescents. Dissertation Abstracts International, 61, 5585.

Van der Kolk, B. A., Roth, S., Pelcovitz, D., Sunday, S., \& Spinazzola, J. (2005). Disorders of extreme stress: The empirical foundation of a complex adaptation to trauma. Journal of Traumatic Stress, 18(5), 389-399. doi:10.1002/jts.20047

Verona, E., Hicks, B. M., \& Patrick, C. J. (2005). Psychopathy and Suicidality in Female 
Offenders: Mediating Influences of Personality and Abuse. Journal of Consulting and Clinical Psychology, 73(6), 1065-1073. doi:10.1037/0022-006X.73.6.1065

Vitacco, M. J., Neumann, C. S., \& Jackson, R. L. (2005). Testing a four-factor model of psychopathy and its association with ethnicity, gender, intelligence, and violence. Journal of Consulting and Clinical Psychology, 73(3), 466. doi:10.1037/0022-006x.73.3.466

Vitacco, M. J., Rogers, R., Neumann, C. S., Harrison, K. S., \& Vincent, G. (2005). A comparison of factor models on the PCL-R with mentally disordered offenders: The development of a fourfactor model. Criminal Justice and Behaviour, 32(5), 526-545. doi:10.1177/0093854805278414

Walker, B. R., \& Jackson, C. J. (2016). Moral emotions and corporate psychopathy: A review. Journal of Business Ethics, 1-14. doi:10.1007/s10551-016-3038-5

Warren, J. I., \& South, S. C. (2006). Comparing the Constructs of Antisocial Personality Disorder and Psychopathy in a Sample of Incarcerated Women. Behavioral Sciences \& The Law, 24(1), 1-20. doi:10.1002/bsl.663

Weiler, B. L., \& Widom, C. S. (1996). Psychopathy and violent behaviour in abused and neglected young adults. Criminal Behaviour and Mental Health, 6(3), 253-271. doi:10.1002/cbm.99

Werner, K. B., Few, L. R., \& Bucholz, K. K. (2015). Epidemiology, comorbidity, and behavioral genetics of antisocial personality disorder and psychopathy. Psychiatric Annals, 45(4), 195199. doi:10.3928/00485713-20150401-08

Widom CS. Childhood victimization and adolescent problem behaviours (1994). In: R. D., Ketterlinus, M. E. Lamb, (Eds.). Adolescent problem behaviours (pp. 127-164). Hillsdale (NJ): Lawrence Erlbaum.

World Health Organisation: International Classification of External Causes of Injuries (ICECI) Version 1.2. Edited by: Amsterdam CSI, Adelaide ANISU. 2004 
Yang, Y., \& Raine, A. (2009). Prefrontal structural and functional brain imaging findings in antisocial, violent, and psychopathic individuals: a meta-analysis. Psychiatry Research: Neuroimaging, 174(2), 81-88.

Yildirim, B. O., \& Derksen, J. J. L. (2015). Clarifying the heterogeneity in psychopathic samples: Towards a new continuum of primary and secondary psychopathy. Aggression and Violent Behaviour, 24, 9-41. doi:10.1016/j.avb.2015.05.001

Zwets, A. J., Hornsveld, R. H., Neumann, C., Muris, P., \& van Marle, H. J. (2015). Assessment, Research \& Evaluation, 12(4), 1-8 
Figure 1

Studies included in the systematic review $(n=58) . N B$ : Full reference details are included in the reference list.

Andrade, J. T. (2010)

Bernstein, D. P., Stein, J. A., \& Handelsman, L. (1998)

Blonigen, D. M., Sullivan, E. A., Hicks, B. M., \& Patrick, C. J. (2012)

Campbell, M. A., Porter, S., \& Santor, D. (2004)

Christopher, K., Lutz-Zois, C. J., \& Reinhardt, A. R. (2007)

Cima, M., Smeets, T., \& Jelicic, M. (2008)

Craparo, G., Schimmenti, A., \& Caretti, V. (2013)

Dargis, M., Newman, J., \& Koenigs, M. (2015)

Daversa, M. T., \& Knight, R. A. (2007)

Edwards, J. D. (2013)

Fingerson, S. H. (2008)

Fisher, A. G. (2004)

Forouzan, E., \& Nicholls, T. L. (2015)

Frodi, A., Dernevik, M., Sepa, A., Philipson, J., \& Bragesjö, M. (2001)

Gao, Y., Raine, A., \& Schug, R. A. (2011)

Gao, Y., Raine, A., Chan, F., Venables, P. H., \& Mednick, S. A. (2010)

Graham, N., Kimonis, E. R., Wasserman, A. L., \& Kline, S. M. (2012)

Hicks, B. M., Vaidyanathan, U., \& Patrick, C. J. (2010)

Hunter, J., Figueredo, A., \& Malamuth, N. (2010)

Kerig, P. K., Bennett, D. C., Thompson, M., \& Becker, S. P. (2012)

Kimonis, E. R., Frick, P. J., Cauffman, E., Goldweber, A., \& Skeem, J. (2012)

Kimonis, E. R., Skeem, J. L., Cauffman, E., \& Dmitrieva, J. (2011)

Kimonis, E., Cross, B., Howard, A., \& Donoghue, K. (2013)

King, A. R. (2014)

Koivisto, H., \& Haapasalo, J. (1996)

Kolla, N. J., Gregory, S., Attard, S., Blackwood, N., \& Hodgins, S. (2014)

Kolla, N. J., Malcolm, C., Attard, S., Arenovich, T., Blackwood, N., \& Hodgins, S. (2013)

Krischer, M. K., \& Sevecke, K. (2008)

Krstic, S., Knight, R. A., \& Robertson, C. A. (2015)

Lang, S., af Klinteberg, B., \& Alm, P. (2002) 
Leach, G., \& Meloy, J. R. (1999)

Linden, S. C., Hess, V., \& Jones, E. (2012)

Marshall, L. A., \& Cooke, D. J. (1999)

Moore, R. L. (2005)

Nørbech, P. B., Crittenden, P. M., \& Hartmann, E. (2013)

Ometto, M., Oliveira, P., Milioni, A., Santos, B., Scivoletto, S., Busatto, G., et al (2016)

O'Neill, M. L., Lidz, V., \& Heilbrun, K. (2003)

Pasold, T. L. (2007)

Pham, T. H. (2012)

Poythress, N. G., Skeem, J. L., \& Lilienfeld, S. O. (2006)

Reyes, A. A. (2013)

Sadeh, N., Javdani, S., \& Verona, E. (2013)

Schember, J. J. (2008)

Schimmenti, A., Di Carlo, G., Passanisi, A., \& Caretti, V. (2015)

Schimmenti, A., Passanisi, A., Pace, U., Manzella, S., Di Carlo, G., \& Caretti, V. (2014)

Schraft, C. V. (2015)

Schraft, C. V., Kosson, D. S., \& Mcbride, C. K. (2013)

Serin, R. C. (1991)

Sharf, A., Kimonis, E. R., \& Howard, A. (2014)

Sperry, D. M., \& Gilbert, B. O. (2005)

Stevenson, L. N. (2010)

Tatar II, J., Cauffman, E., Skeem, J., \& Kimonis, E. (2012)

Ullrich, S., \& Marneros, A. (2007)

Valentine, I. S. (2001, April)

Verona, E., Hicks, B. M., \& Patrick, C. J. (2005)

Warren, J. I., \& South, S. C. (2006)

Weiler, B. L. \& Widom, C. S. (1996)

Weizmann-Henelius, G., Gronroos, M., Putkonen, H., Eronen, M. et al (2010) 
Figure 2.

Main themes and subthemes relating to the association between developmental trauma and psychopathy, from Delphi round one

\author{
EMOTIONAL DIFFICULTIES \\ Emotional dysregulation \\ Emotional detachment \\ Reactive aggression \\ Coping
}

CHALLENGED SELF-IMAGE

Self-blame

Disturbed sense of self

Shame

DEVELOPMENTAL TRAJECTORY

Violation of trust/lack of trust development

Attachment problems

Disrupted development

Impact of abuse on brain development

Child's developmental needs not being met due to abuse

CONTEXT

Duration of trauma

Age when abuse began

Trauma severity

Perpetrator of abuse

Role of environment

PREDISPOSING FACTORS

Role of genetics in developing psychopathy

CONSEQUENCES OF ABUSE

Relationship difficulties

Externalising and internalising symptoms (e.g. impulsive/risky behaviour and anxiety)

VIEWS ABOUT THE WORLD

Biased attributions

Normative beliefs

Violation of expectations

Lack of boundary formulation

PROTECTIVE FACTORS

Early intervention after abuse

Survival tactics to cope with abuse

Presence of safe, stable adult 
Table 1.

Percentage change in agreement of items scored in round two $(N=16)$ that were scored again in round three $(N=12)$ of the Delphi study .

\begin{tabular}{llll}
\hline Answer option & $\begin{array}{l}\text { \% Agreement in } \\
\text { round two (N) }\end{array}$ & $\begin{array}{l}\text { \% Disagreement } \\
\text { in round two (N) Agreement in }\end{array}$ & $\begin{array}{l}\% \text { Disagreement } \\
\text { round three (N) } \\
\text { in round three (N) }\end{array}$ \\
\hline $\begin{array}{l}\text { How damaging do you consider sexual abuse? } \\
\text { (agreement columns refer to "very damaging" or "extremely } \\
\text { damaging", disagreement columns refer to "not damaging") }\end{array}$ & $\mathbf{8 7 . 5 ( 1 4 )}$ & 0 & $\mathbf{9 1 . 7}(11)$ \\
\end{tabular}

\begin{tabular}{llcc}
\hline $\begin{array}{l}\text { Developmental trauma can be so damaging to a child due to negative } \\
\text { effects on emotional regulation. }\end{array}$ & $\mathbf{8 7 . 5}(14)$ & $\mathbf{1 0 0}(12)$ & $\mathbf{9 1 . 7}(11)$ \\
\hline $\begin{array}{l}\text { A more severe outcome can occur when the caregiver is the } \\
\text { perpetrator of abuse due to it violating expectations of a caring and } \\
\text { safe environment. }\end{array}$ & $\mathbf{1 0 0}(16)$ & 0 & 0 \\
\hline $\begin{array}{l}\text { A more severe outcome can occur when the caregiver is the } \\
\text { perpetrator of abuse due to interference with the child's view of the } \\
\text { self and the world. }\end{array}$ & $\mathbf{8 7 . 5 ( 1 4 )}$ & 0 & $\mathbf{9 1 . 7}(11)$ \\
\hline $\begin{array}{l}\text { To what level do you agree with attachment disorder as being most } \\
\text { associated with the possibility of psychopathy developing? }\end{array}$ & $\mathbf{8 7 . 5 ( 1 4 )}$ & $6.25(1)$ & $58.4(7)$
\end{tabular}

To what level do you agree that the following components of psychopathy could be most affected by developmental trauma: Lack of remorse

$81.25(13)$

Shallow affect

Early behavioural problems $\mathbf{8 1 . 2 5}(13)$

75 (12)

$6.25(1)$
$6.25(1)$
$6.25(1)$

$50(6)$

$16.67(2)$

$58.33(7)$

83.34 (10) 
To what extent to do you agree that development of hostile world

$81.25(13)$

$6.25(1)$

$83.3(10)$

$8.33(1)$

views could be responsible for a possible link between

developmental trauma and primary psychopathy?

To what extent do you agree with the following (as being responsible

for a possible link between secondary psychopathy and

developmental trauma):

Lack of emotional development

$100(16)$

$93.75(15)$

0

91.67 (11)

$8.33(1)$

Development of a hostile world view

$6.25(1)$

$83.34(10)$

$8.33(1)$

To what extent do you agree that:

Personal/familial abuse could make a child more likely to develop primary psychopathy

Neglect or emotional abuse could make a child more likely to

$81.25(13)$

$87.5(14)$

6.25 (1)

$66.67(8)$

$25(3)$

develop primary psychopathy

To what extent do you agree that interference with the developmental

$81.25(13)$

$6.25(1)$

$66.67(8)$

$16.67(2)$

needs of the child could make a child more likely to develop primary

psychopathy?

To what extent do you agree that:

Physical abuse could make a child more likely to develop secondary

psychopathy

$100(16)$

0

$6.25(1)$

$58.3(7)$

$25(3)$

Neglect or emotional abuse could make a child more likely to

develop secondary psychopathy

$100(16)$

0

$66.67(8)$

$24.99(2)$

Sexual abuse could make a child more likely to develop secondary psychopathy

$100(16)$

$75(9)$

$8.33(1)$

To what extent do you agree that lack of emotional development

$81.25(14)$

0

$58.34(7)$

$16.66(2)$

(from trauma) could make a child more likely to develop secondary

psychopathy? 
To what extent do you agree that the duration of developmental trauma can increase the possibility of psychopathy emergence?

93.75 (15)

0

$66.7(8)$

$16.66(2)$

\begin{tabular}{|c|c|c|c|c|}
\hline $\begin{array}{l}\text { To what extent do you agree that the intensity of trauma can increase } \\
\text { the possibility of psychopathy emergence? }\end{array}$ & $93.75(15)$ & 0 & $66.7(8)$ & $16.7(2)$ \\
\hline $\begin{array}{l}\text { To what extent do you agree that: } \\
\text { Betrayal trauma could affect the possibility of psychopathy emerging } \\
\text { due to a child developing emotional numbing as a defence } \\
\text { mechanism to deal with the negative effects of trauma. This in turn } \\
\text { impacts negatively on their ability to develop emotions connecting to } \\
\text { caring about others. }\end{array}$ & 81.25 (14) & $6.25(1)$ & 83.33 (10) & $8.33(1)$ \\
\hline $\begin{array}{l}\text { Betrayal trauma could affect the possibility of psychopathy emerging } \\
\text { due to the lack of trust developing during childhood as a result of the } \\
\text { trauma, which then affects future relationships and social } \\
\text { interactions. }\end{array}$ & & & & \\
\hline $\begin{array}{l}\text { It is likely a child with developmental trauma could develop } \\
\text { secondary psychopathy. }\end{array}$ & $62.5(10)$ & $18.8(3)$ & $66.7(8)$ & $33.3(4)$ \\
\hline $\begin{array}{l}\text { It is likely a child with developmental trauma could develop primary } \\
\text { psychopathy. }\end{array}$ & $43.8(7)$ & $41.7(5)$ & $58.3(7)$ & $31.3(5)$ \\
\hline
\end{tabular}

Note. Numbers in bold represent those which have reached over the cut off (70\%) for consensus of opinion. As this is considering agreement and disagreement, the neutral option is not included; therefore the percentages will sometimes not total 100. 
Table 2.

Final items that were checked for \% consensus of agreement in round three of the Delphi study $(N=12)$

\begin{tabular}{|c|c|c|c|}
\hline Item checked for final consensus & $\%$ Agreement (N) & $\%$ Disagreement $(\mathbf{N})$ & $\begin{array}{l}\text { Examples of comments } \\
\text { made when disagreeing }\end{array}$ \\
\hline $\begin{array}{l}\text { A more severe outcome can occur when the caregiver is the } \\
\text { perpetrator due to it strongly impacting on the child's development } \\
\text { of trust. }\end{array}$ & $91.7(11)$ & $8.3(1)$ & $\begin{array}{l}\text { "This is a reasonable } \\
\text { hypothesis, but there is no } \\
\text { data of which I am aware to } \\
\text { support this conclusion." }\end{array}$ \\
\hline
\end{tabular}


"This is a reasonable

hypothesis, but there is no data of which I am aware to support this conclusion."

Social and relationship problems (as a symptom of trauma) could

$75(9)$ be most associated with the possibility of psychopathy developing.
$25(3)$
"Psychopathy is mostly heritable."

"The neurobiological evidence clearly supports two opposite responses in the amygdala to trauma/abuse and

psychopathy. You can't have simultaneous increased and decreased amygdala response. This is what people want to believe, not what the data says."

"I'm not well informed about

this issue."

Do you agree with the below components as being rated most affected by developmental trauma:

Callousness and lack of empathy

$75(9)$

$91.7(11)$

Poor behavioural control
"My team's own research and

clinical experience suggests

that for many survivors of

child abuse they have greater

levels of empathy for others

compared to controls; it is

possible that if a child was

abused for an extended period

at a young age they may have

a predominantly dissociative

coping response, in turn this

may increase lack of empathy, but this is not the norm." 
"There may be some

disinhibition or poor impulse control but there may also be calculated behaviour towards antisocial goals which imply strong control."

Lack of emotional development could be responsible for a possible $\mathbf{7 5}$ (9)

link between developmental trauma and primary psychopathy.

Do you agree that the following could be responsible for a possible

link between developmental trauma and secondary psychopathy:

Difficulties with self-regulation

Disinhibited behaviour

A combination of multiple abuse types could make a child more

likely to develop primary psychopathy.
(11)

$91.7(11)$

$83.3(10)$

$8.3(1)$

$16.7(2)$

"It is more about an impaired development of emotional regulation than a deficit in experience of emotion."

"Secondary psychopathy is simply antisocial behaviour in the absence of psychopathic traits."

"It is possible, but then lots of things are; ... what abuse, when, what was the environmental response, what are the other primary relationships in the child's life, what is the temperament of the child prior to the abuse, etc."

The lack of emotional development from the trauma could make a child more likely to develop primary psychopathy.

"Again, it is more an issue of emotion regulation, not a deficit in experience of emotion."

The impact the abuse has on personality developing could make a child more likely to develop primary psychopathy.

$83.3(10)$

"Any link between trauma and psychopathic personality (primary) is highly likely to be mediated by a number of inter-related factors - this is 
definitely clinical anecdote, but available research would give this inference too."

A combination of multiple abuse types could make a child more likely to develop secondary psychopathy. trauma) could make a child more likely to develop secondary psychopathy.

Betrayal trauma can affect the possibility of psychopathy emerging through the disruption it causes to attachment.
$91.7(11) \quad 8.3(1)$

$91.7(11)$

$8.3(1)$

"Secondary psychopathy is simply antisocial behaviour in the absence of psychopathic traits."

"Secondary psychopathy is simply antisocial behaviour in the absence of psychopathic traits."

"There is no evidence for this position."

"Not really, it could just as likely and often more likely, result in an individual who is craving connection with others but just does it in a maladaptive way."

\footnotetext{
Note. Numbers in bold represent those which have reached over the cut off (70\%) for consensus of opinion. As this is considering agreement and disagreement, the neutral
} option is not included; therefore the percentages will sometimes not total 100. 
Table 3.

Developmental trauma across those with psychopathy and those with Antisocial/ Dissocial personality disorder.

\begin{tabular}{|c|c|c|c|}
\hline \multicolumn{4}{|c|}{ Psychopathic ( $\mathrm{n}=17 ; 13$ psychopathic, 4 not psychopathic) } \\
\hline & & Psychopathic $(\mathrm{n} / \%)$ & Not psychopathic $(\mathrm{n} / \%)$ \\
\hline \multirow{8}{*}{$\begin{array}{l}\text { Developmental } \\
\text { Trauma (DT) }\end{array}$} & Any & $10(76.9)$ & $3(75)$ \\
\hline & No & $3(23.1)$ & $1(25)$ \\
\hline & Physical & $9(69.2)$ & $3(75)$ \\
\hline & Sexual & $5(38.5)$ & $2(50)$ \\
\hline & Neglect/emotional & $10(76.9)$ & $3(75)$ \\
\hline & Multiple & $9(69.2)$ & $3(75)$ \\
\hline & \multicolumn{3}{|c|}{ Antisocial Personality Disorder $(\mathrm{n}=66,40$ APD, 26 no APD) } \\
\hline & & $\operatorname{APD}(\mathrm{n} / \%)$ & No APD $(\mathrm{n} / \%)$ \\
\hline \multirow{6}{*}{$\begin{array}{l}\text { Developmental } \\
\text { Trauma (DT) }\end{array}$} & Any & $36(90)$ & $24(92.4)$ \\
\hline & No & $4(10)$ & $2(8.3)$ \\
\hline & Physical & $31(77.5)$ & $17(65.4)$ \\
\hline & Sexual & $18(45)$ & $12(46.2)$ \\
\hline & Neglect/emotional & $33(82.5)$ & $23(88.5)$ \\
\hline & Multiple & $30(75)$ & $18(69.2)$ \\
\hline & & $\begin{array}{l}\text { APD mean trauma score } \\
\text { (SD) }\end{array}$ & $\begin{array}{l}\text { No APD mean trauma score } \\
\text { (SD) }\end{array}$ \\
\hline \multirow{4}{*}{$\begin{array}{l}\text { Developmental } \\
\text { trauma (DT) } \\
\text { severity score }\end{array}$} & Physical & $2.2(1.42)$ & $1.65(1.41)$ \\
\hline & Sexual & $1.53(1.89)$ & $1.35(1.62)$ \\
\hline & Neglect/emotional & $1.85(1.33)$ & $2.23(1.39)$ \\
\hline & Overall DT & $1.86(1.14)$ & $1.74(1.14)$ \\
\hline
\end{tabular}


Table 4.

Linear regression analyses examining Developmental Trauma (DT) severity scores as predictor variables for total PCL-R, factor one and factor two scores.

\begin{tabular}{|c|c|c|c|c|c|c|c|}
\hline & & B & SE B & $\boldsymbol{\beta}$ & $\mathbf{R}^{2}$ & $\mathbf{R}^{\mathbf{2}}$ Adjusted & $\mathbf{F}$ \\
\hline & DT type & & & & & & \\
\hline & $\begin{array}{l}\text { Physical DT } \\
\text { severity }\end{array}$ & .05 & 1.05 & .01 & .00 & -.07 & .002 \\
\hline \multirow{4}{*}{$\begin{array}{l}\text { Total } \\
\text { PCL-R } \\
\text { scores }\end{array}$} & $\begin{array}{l}\text { Sexual DT } \\
\text { severity }\end{array}$ & -.001 & .77 & .00 & .00 & -.07 & 0 \\
\hline & $\begin{array}{l}\text { Neglect/Emotional } \\
\text { DT severity }\end{array}$ & .62 & 1.13 & .15 & .02 & -.05 & .30 \\
\hline & $\begin{array}{l}\text { Overall DT } \\
\text { severity }\end{array}$ & .67 & 1.15 & .15 & .02 & -.05 & .34 \\
\hline & $\begin{array}{l}\text { Physical DT } \\
\text { severity }\end{array}$ & 2.31 & 1.01 & .52 & .28 & .22 & $5.29 *$ \\
\hline \multirow[t]{4}{*}{$\begin{array}{l}\text { Factor } 1 \\
\text { scores }\end{array}$} & $\begin{array}{l}\text { Sexual DT } \\
\text { severity }\end{array}$ & -.12 & .86 & -.04 & .001 & -.07 & .02 \\
\hline & $\begin{array}{l}\text { Neglect/Emotional } \\
\text { DT severity }\end{array}$ & 1.78 & 1.18 & .37 & .14 & .08 & 2.26 \\
\hline & $\begin{array}{l}\text { Overall DT } \\
\text { severity }\end{array}$ & 1.81 & 1.21 & .37 & .14 & .08 & 2.24 \\
\hline & $\begin{array}{l}\text { Physical DT } \\
\text { severity }\end{array}$ & 3.30 & 1.07 & .64 & .41 & .36 & $9.54 * *$ \\
\hline \multirow[t]{3}{*}{$\begin{array}{l}\text { Factor } 2 \\
\text { scores }\end{array}$} & $\begin{array}{l}\text { Sexual DT } \\
\text { severity }\end{array}$ & .90 & .98 & .24 & .06 & -.01 & .84 \\
\hline & $\begin{array}{l}\text { Neglect/Emotional } \\
\text { DT severity }\end{array}$ & 2.60 & 1.31 & .48 & .23 & .18 & 4.19 \\
\hline & $\begin{array}{l}\text { Overall DT } \\
\text { severity }\end{array}$ & 3.37 & 1.24 & .59 & .35 & .30 & $7.41 *$ \\
\hline
\end{tabular}

$* p<.05 * * p<.01$ 